NBER WORKING PAPER SERIES

\begin{abstract}
DEFICITS, CROWDING OUT AND INFLATION:
THE SIMPLE ANALYTICS
\end{abstract}

Willem H. Buiter

Working Paper No. 1078

NATIONAL BUREAU OF ECONOMIC RESEARCH

1050 Massachusetts Avenue

Cambridge MA 02138

February 1983

The research reported here is part of the NBER's research program in Financial Markets and Monetary Economics. Any opinions expressed are those of the author and not those of the National Bureau of Economic Research. 
NBER Working Paper $\# 1078$

February 1983

Deficits, Crowding out and Inflation: The Simple Analytics

\section{Abstract}

The paper studies the relationship between public sector financial deficits, crowding-out of public sector capital formation and inflation in a number of small, classical macroeconomic models. This amounts to reworking some of the government budget constraint literature by including capacity constraints, flexible prices and rational expectations. After considering some simple "money only" and "money-capital" models, most of the paper is devoted to the analys is of a continuous time representation of the "money-bonds-capital" model of Sargent and Wallace. It is noted that the conventionally measured deficit is likely to be a poor indicator both of the "eventual monetization" implied by the fiscal stance and of the longrun financial crowding-out pressure it represents. A better measure would be the inflation-and-real-growth-corrected, cyclically adjusted ("permanent") government currect account deficit as a proportion of national income.

It is also suggested that the Sargent-Wallace "paradox" - in the variable velocity model, lower monetary growth now may mean higher inflation now and in the future - has its counterpart in the possibility that lower money growth now may give lower inflation now and in the future. In the constant velocity model the Sargent-Wallace findings are confirmed when the real interest rate is made endogenous.

Willem H. Buiter London School of Economics Houghton Street London WC2A 2AE, England 


\title{
Deficits, Crowding out and Inflation: The Simple Analytics
}

\author{
Willem H. Buiter * \\ LSE and NBER
}

\section{Contents/}

1. Introduction

2. Deficits, inflation and crowding out in closed economies without government bonds

(a) Models with neither government bonds nor private capital

(b) Models without government bonds but with private capital

3. Deficits, inflation and crowding out in closed economies with government bonds.
(a) The model of Sargent and Wallace
(b) Does tighter money now mean higher inflation in the future?
(c) An endogenous real interest rate
(d) Public sector capital formation
(e) Cyclical corrections

4. Conclusion 



\section{INTRODUCTION}

This paper investigates the relationship between monetary growth, government deficits and crowding out. Public sector deficits, if not quite the root of all evil, are nevertheless frowned upon, condemned and combated by finance ministers, central bankers and heads of international financial institutions. The case against government deficits can be briefly stated as follows:

Deficits must be financed by borrowing or "high-powered" domestic credit expansion. In a closed economy or an open economy with a freely floating exchange rate, "high-powered" domestic credit expansion equals the rate of change of the monetary base. If deficits are financed by printing money, this will fuel inflation. If they are financed by borrowing this will put upward pressure on interest rates, leading to "crowding out" of interestsensitive spending. Even at given interest rates "crowding out" could cccur, with government bonds displacing claims to private capital in private portfolios.

Like most conventional wisdom in economics, the account of the money growth - deficit - crowding out nexus just given is a (potentially dangerous) half-truth. The correct relationships are fortunately quite easily derived. They involve no more than a "dusting off" of the government budget constraint literature with allowance for real growth, inflation, public sector capital formation, and cyclical deviations of actual from trend output (Blinder and Solow (1973), Buiter (1977a, b), (1979), Tobin and Buiter $(1976,1980)$.

The paper analyses the implications of government deficits in a number 
of familiar macroeconomic models. Three limitations, to be remedied in future research, stand out. First, only closed economies are modelled. Second, "money" is identified throughout with the monetary base. Private money is not considered. Third, only full employment models are considered. Even with these restrictions, a number of important issues can be dealt with. The plan of the paper is as follows: Section 2 considers models without public sector interest-bearing debt. After analysing a model in which money is the only asset, two models with money and real capital are studied. Section 3 considers models with money, real capital and public sector interest-bearing debt. This whole section is organised around the seminal paper of Sargent and Wallace (1981) in which rational expectations met the government budget constraint. It is noted in Section (3a) that it is necessary to correct the conventionally measured deficit for changes in the real value of government interest-bearing debt due to inflation to obtain a proper measure both of the "crowding out pressure" and of the eventual monetisation implied by the fiscal stance. In Section (3b) the SargentWallace "paradox" that lower monetary growth now may mean higher future inflation and even, with velocity endogenous, higher inflation now is analysed. It is argued that a "counter-paradox" - lower monetary growth now leading to lower inflation now and in the future - can also occur when velocity is endogenous. A diagrammatic description of this phenomenon is provided. In Section (3c) it is shown that the exogenous real interest rate of the Sargent-Wallace model can be endogenised without changing its qualitative conclusions in the case when velocity is constant. Public sector capital formation is introduced in Section (3d). It is argued that (with proper allowance for any difference between the appropriated rate of return on public sector capital and the government's cost of borrowing) it is the government's current account deficit that matters for future inflation and 
for crowding out of total (private plus public) capital formation. Finally, in Section (3e) we consider cyclical variations in the deficit without (necessarily) viewing departures of actual from trend output as due to Keynesian fluctuations in effective demand.

The conclusion is that the deficit measure that should be the focus of concern is the inflation-and-real-growth-corrected, cyclically adjusted government current account deficit. I have shown elsewhere that this measure can differ quite strikingly from the conventionally measured government deficit (Buiter (1981, 1982c)). 


\section{DEFICITS, INFLATION AND CROWDING OUT IN CLOSED ECONOMIES}

WITHOUT GOVERNMENT BONDS

(2a) Models with neither government bonds nor private capital

Consider the world's simplest economy. The income velocity of circulation of money, $V$, is constant as is the rate of growth $n$ of real output, $Y$. G denotes public spending on-goods and services and $T$ taxes net of transfers. The price level, $P$, is perfectly flexible. Money, $M$, is the only government liability and the only private sector asset.

$$
M V=P Y
$$

$$
\begin{aligned}
& V=\bar{V} \\
& \dot{Y}=n \\
& \frac{\dot{M}}{P}=G-T
\end{aligned}
$$

It follows immediately that

$$
\frac{\dot{p}}{\bar{P}}=\frac{\dot{M}}{M}-n=V\left(\frac{G-T}{Y}\right)-n \equiv V(g-\tau)-n
$$

At each moment, the rate of inflation equals the proportional rate of growth of the nominal money stock minus the rate of growth of output. We define $g \equiv G Y^{-1}$ and $\tau=T Y^{-1}$. The proportional rate of growth of the nominal money stock can be expressed as the product of the velocity of circulation and the public sector deficit as a proportion of GNP. With velocity constant, an increase in the deficit relative to GNP raises inflation. The deficit, as a proportion of GNP, consistent with any rate of inflation $\left(\frac{\dot{p}}{P}\right)^{*}$ is given by

$$
g-\tau=\left(\left(\frac{\dot{P}}{P}\right)^{\star}+n\right) V^{-1}
$$

e.g. the zero inflation deficit is given by $\mathrm{nV}^{-1}$. Note that in the U.K. the annual velocity of circulation of base money is about 20 while Mi velocity is 
about 7 and M3 velocity about $3.5 .^{\star} \quad$ With a natural rate of growth of 2 to $3 \%$ per year, one's estimate of the zero-inflation deficit in a "pre-Ricardian" U.K. economy therefore ranges between .1 and .9 per cent of GNP.

There is no role for private capital formation in this model, so the "crowding out" issue is moot. Let $C$ denote private consumption and S private saving. Then $Y=C+G$ and $S=Y-T-C=\frac{\dot{M}}{p}$. With output exogenous, public spending displaces private consumption one for one. Private consumption is unaffected by changes in taxes. An increase in taxes lowers private saving (here equal to the private sector financial surplus) and the public sector financial deficit equally. Real private financial wealth, $\frac{M}{P}$ is constant.

If we make the velocity of circulation endogenous, the relationship between changes in the deficit and the rate of inflation may appear to become ambiguous. An increase in $g-\tau$ might be offset by a decrease in velocity sufficiently large to result in a net negative effect on inflation.

Retaining the assumption that money is the only asset we replace (2) by

(2') $\quad v=v\left(\frac{\hat{p}(t, t)}{p(t, t)}\right) \quad v^{\prime} \geqslant 0$

For any variable $x, x(s, t)$ denotes its value expected, at time $t$, to prevail at time s. We assume that the past and present are known i.e. $\hat{x}(s, t)=x(s)$ for $s \leqslant t$

Velocity as a non-decreasing function of the expected rate of inflation does not, of course, follow inevitably from rational optimising behaviour. The model of equations (1), ( $\left.2^{\prime}\right),(3)$ and (4) can be viewed as the continuous time analogue of the discrete time overlapping generations model in which money is the only store of value, population grows at a rate $n$ and per-capita endowments are constant. The effect of anticipated inflation on the demand for money in such 
models is simply the effect on saving of the anticipated real rate of return. Substitution and income effects pull in opposite directions.

For most plausible expectations mechanisms, the long run (or steady state) actual and expected rates of inflation coincide. With $\frac{\hat{p}}{p}=\frac{\dot{p}}{p}$ we obtain

$$
\left.\frac{d\left(\frac{\dot{P}}{p}\right)}{d(g-\tau)}\right|_{L R}=\frac{V}{1-V^{\prime}(g-\tau)}
$$

If the initial equilibrium is characterised by a deficit $(g-\tau>0)$ then an increase in the deficit-GNP ratio could lower the long-run rate of inflation if velocity were sufficiently responsive to the expected rate of inflation: $v^{\prime}>(g-\tau)^{-1}$ or $\left(\frac{\dot{p}}{p}+n\right) \frac{V^{\prime}}{V}>1$ - a greater than unitary inflation elasticity of velocity.

This apparent anomaly, however, can be shown to imply indeterminacy in the behaviour of the system under rational expectations.

We can solve (1) and $\left(2^{\prime}\right)$ for $\frac{\hat{\dot{p}}}{\mathrm{P}}$ as a function of $m \equiv \frac{M}{\mathrm{PY}}$. This yields

$$
\frac{\hat{\dot{P}}(t, t)}{\hat{P}(t, t)}=\dot{\phi}(m(t)) \quad \text { with } \dot{\phi}^{\prime}=-\frac{v^{2}}{V^{\prime}} \leq 0
$$

$m$ is a non-predetermined state variable: $p$ can move discontinuously in response to current and anticipated future shocks. Since $\dot{m}=g-\tau-\left(\frac{\dot{p}}{p}+n\right) m$, the forward-looking rational expectations solution for $m$ in the neighbourhood of a stationary equilibrium $\bar{m}$ is given by

$$
\begin{aligned}
& m(t)=c_{0} e^{\lambda t}-\int_{t}^{\infty} e^{\lambda(t-u)}(\hat{g}(u, t)-\hat{\tau}(u, t)) d u \text { * } \\
& \lambda=-\left[\left(\frac{\bar{p}}{p}\right)+n-\frac{\left.v\left(\frac{\bar{p}}{p}\right)\right]}{\left.v^{\prime}\left(\frac{\dot{\bar{p}}}{p}\right)\right)}\right]
\end{aligned}
$$


$\mathrm{C}_{0}$ is the constant of integration. For there to be a unique convergent forward-looking solution we require $\lambda>0$ and $c_{0}=0$. Since $\frac{\dot{p}}{p}+n=(g-\tau) V$, the condition $\lambda>0$ is equivalent to $V^{\prime}(g-\tau)<1$. From equation (7) we see that this rules out a negative effect of an increase in the deficit-GNP ratio on the long-run rate of inflation.

The change in the real value of the government's nominal liabilities (only money is this model) is not a useful indicator of the behaviour of the rate of inflation, in the short-run or in the long-run. The stationary equilibria of both the constant velocity and variable velocity models have a constant stock of real money balances per unit of output $m$; real money balances grow at the natural rate $n$. In the constant velocity model $m$ is the same regardless of the rate of inflation.

In the variable velocity model we know from equation (8) that whenever expectations of the future are not being revised(i.e. except for those instants at which 'news' arrives), $m(t)$ and $\frac{\dot{p}(t)}{p(t)}$ are inversely correlated. Setting $c_{0}$ equal to zero in (9a) and differentiating we obtain.

$$
\frac{\dot{m}(t)}{m(t)}=\lambda+\frac{g(t)-\tau(t)}{m(t)}-\frac{1}{m(t)} \int_{t}^{\infty} e^{\lambda(t-u)} \frac{\partial}{\partial t}(\hat{g}(u, t)-\hat{\tau}(u, t)) d u
$$

Since $\frac{\dot{p}}{p}=\frac{g-\tau}{m}-\frac{\dot{m}}{m}-n$

$$
\frac{\dot{p}}{p}=-\lambda-n+\frac{1}{m(t)} \int_{t}^{\infty} e^{\lambda(t-u)} \frac{\partial}{\partial t}(\hat{g}(u, t)-\hat{\tau}(u, t)) d u
$$

The last term on the right-hand-side of (10) and (11) contains the effect of revisions, at time $t$, in expectations about the future course of the deficit. At those instants that news arrives, $P$ may jump discontinuously. $\frac{m}{P}$ obviously "jumps" in the opposite direction. On the adjustment path, when no news arrives the rate of inflation is given by $\frac{\dot{p}}{p}=-(\lambda+n)$ while the rate of change 
of real money balances per unit of output is an increasing function of the deficit-GNP ratio.

As suggested in the introduction, the "inflation correction" to be applied to the deficit in order to evaluate its long-run implications for money growth consists in subtracting from the flow-of-funds measure the inflation-induced reduction in the real value of the government's interestbearing debt only. The "inflation tax' on the stock of high-powered money should not be subtracted.

(2b) Models without government bonds but with private capital

A money-capital model without intrinsically valuable money

A negative long-run effect on the rate of inflation in response to an increase in the deficit occurs in the simplest money-capital model. $\tilde{k}$ denotes the capital labour ratio, $\tilde{m}$ the stock of real money balances per worker, $\tilde{g}$ real spending per worker, $\tilde{\tau}$ lump-sum taxes per worker, $s$ the private savings rate $(0<s<1)$, and $\tilde{y}=f(\tilde{k})\left(f^{\prime}>0, f^{\prime \prime}<0\right)$ output per worker. Money is assumed not to yield any intrinsic, direct utility so it will be held only if its rate of return equals that obtainable by holding real capital, i.e.

$$
-\left(\frac{\hat{\dot{p}}}{p}\right)=f^{\prime}(\tilde{k}) \stackrel{*}{\star}
$$

The equations of motion for $\tilde{k}$ and $\tilde{m}$ are given by

$$
\begin{aligned}
& \dot{\tilde{k}}=s(f(\tilde{k})-\tilde{\tau})-n \tilde{k}-(\tilde{g}-\tilde{\tau}) \\
& \dot{\tilde{m}}=\tilde{g}-\tilde{\tau}-\left(\frac{\dot{p}}{p}+n\right) \tilde{m}
\end{aligned}
$$

In this model an increase in the deficit, whether brought about by raising $\tilde{g}$ or by lowering $\tilde{\tau}$, lowers the long-run capital-labour ratio and the rate of

* This model can be viewed as the continuous time representation of an overlapping generations model with a Cobb-Douglas production function and homothetic preferences. Note that if the constraint $f^{\prime} \geqslant 0$ applies, we can never observe an economy with a positive rate of inflation. Instead the price of money falls to zero ( $p$ tends to infinity) and the model reduces to the familiar one sector Solow-Swan harter model. Therefore, if money is held in the steady state, we have $\frac{\tilde{q}-\tilde{\tau}}{\tilde{m}}<n$. 
$-9-$

inflation if $s f^{\prime}-n<0$ and the real per-capita stock of money if $s f^{\prime}-n<0$ and $f^{\prime}-n>0$. The first of these conditions is the local stability condition in the simple Solow-Swan growth model; it also ensures locally stable behaviour for $k$ in the present model. The second condition rules out dynamic inefficiency of the stationary equilibrium. Given these conditions the long-run multipliers are:

(14a) $\quad \frac{d \tilde{k}}{d \tilde{g}}=\frac{1}{s f^{\prime}-n}<0$

(14b) $\quad \frac{d\left(\frac{\dot{p}}{p}\right)}{d \tilde{g}}=\frac{-f^{\prime \prime}}{s f^{\prime}-n}<0$

(14c) $\quad \frac{d \tilde{m}}{d \tilde{g}}=\frac{-\left(s f^{\prime}-n+\tilde{m} f^{\prime}\right)}{\left(s f^{\prime}-n\right)\left(f^{\prime}-n\right)}<0$

(14d) $\frac{d \tilde{k}}{d(-\tilde{\tau})}=\frac{i-s}{s f^{\prime}-n}<0$

(14e) $\quad \frac{d\left(\frac{\dot{p}}{p}\right)}{d\left(-\frac{\tau}{\tau}\right)}=\frac{-f^{\prime \prime}(1-s)}{s f^{\prime}-n}<0$

(14f) $\quad \frac{d \tilde{m}}{d(-\tau)}=\frac{-\left(s f^{\prime}-n+(7-s) \tilde{m} f^{\prime}\right)}{\left(s f^{\prime}-n\right)\left(f^{\prime}-n\right)}<0$

Across steady states the rate of inflation moves in the same direction as the capital labour ratio. A lower value of $k$ raises the marginal product of capital. To preserve portfolio balance the real rate of return on money balances has to rise pari-passu. This is achieved by a lower rate of inflation. Note that both spending increases and tax cuts crowd out capital in the long-run, as does a balanced budget (or constant deficit) increase in spending. 
The linearised version of the model in a neighbourhood of the steady state equilibrium is

$$
\left(\begin{array}{l}
\dot{\tilde{k}} \\
\dot{\tilde{m}}
\end{array}\right)=\left(\begin{array}{cc}
s f^{\prime}-n & 0 \\
\tilde{m} f^{\prime \prime} & f^{\prime}(\tilde{k})-n
\end{array}\right)\left(\begin{array}{l}
\tilde{k} \\
\tilde{m}
\end{array}\right)+\left(\begin{array}{cc}
-1 & 1-s \\
1 & -1
\end{array}\right)\left(\begin{array}{l}
\tilde{g} \\
\tilde{\tau}
\end{array}\right)
$$

There is one predetermined variable $\tilde{k}$ and one non-predetermined variable $\tilde{m}$. For a unique convergent solution to exist, the equilibrium must be a saddlepoint. The two characteristic roots of the system are $\lambda_{1}=s f^{\prime}-n$ and $\lambda_{2}=f^{\prime}-n$. $\lambda_{1}<0$ and $\lambda_{2}>0$ are necessary and sufficient for (15) to have a saddlepoint equilibrium with $k$ predetermined.

The general solution is given by

$$
\begin{aligned}
& \tilde{m}(t)=\frac{\tilde{m} f^{\prime \prime}}{(s-1) f^{\top}} \tilde{k}(t)-\int_{t}^{\infty} e^{\lambda_{2}(t-u)}\left[\left(1+\frac{\tilde{m} f^{\prime \prime}}{(s-1) f^{\top}}\right) \tilde{\tilde{g}}(u, t)-\left(1-\frac{\tilde{m} f^{\prime \prime}}{f^{\prime}}\right) \hat{\tilde{\tau}}(u, t)\right] d u \\
& \tilde{k}(t)=e^{\lambda_{1}\left(t-t_{0}\right)} \tilde{k}\left(t_{0}\right)-\int_{t_{0}}^{t} e^{\lambda_{1}(t-u)}(\tilde{g}(u)-(1-s) \tilde{\tau}(u)) d u
\end{aligned}
$$

The impact effect of an unanticipated permanent increase in the deficit on the rate of inflation is analysed in Figure 1 . The qualitative features of the saddlepoint equilibrium are sketched in Figure la with the unique convergent trajectory given by SS. In Figure $1 b$, starting from $E_{j}$, the increase in the deficit is followed immediately by a jump increase in the price level which lowers real money balances per-capita to $E_{12}$. After that the capital-labour ratio and the rate of inflation decline smoothly along $S$ 'S' towards $E_{2}$. In Figure $i c$ there is an immediate jump decline in the price level to $E_{12}$ followed again by a gradual decline in $\tilde{k}$ and $\frac{\dot{p}}{p}$ towards $E_{2}$. Note that in this model along the saddlepath SS', the rate of inflation and the stock of real percapita money balances are positively related, unlike the variable velocity model of Section 2a. 


\section{FIGURE 1}

The effect of an unanticipated permanent increase in the deficit

(a)

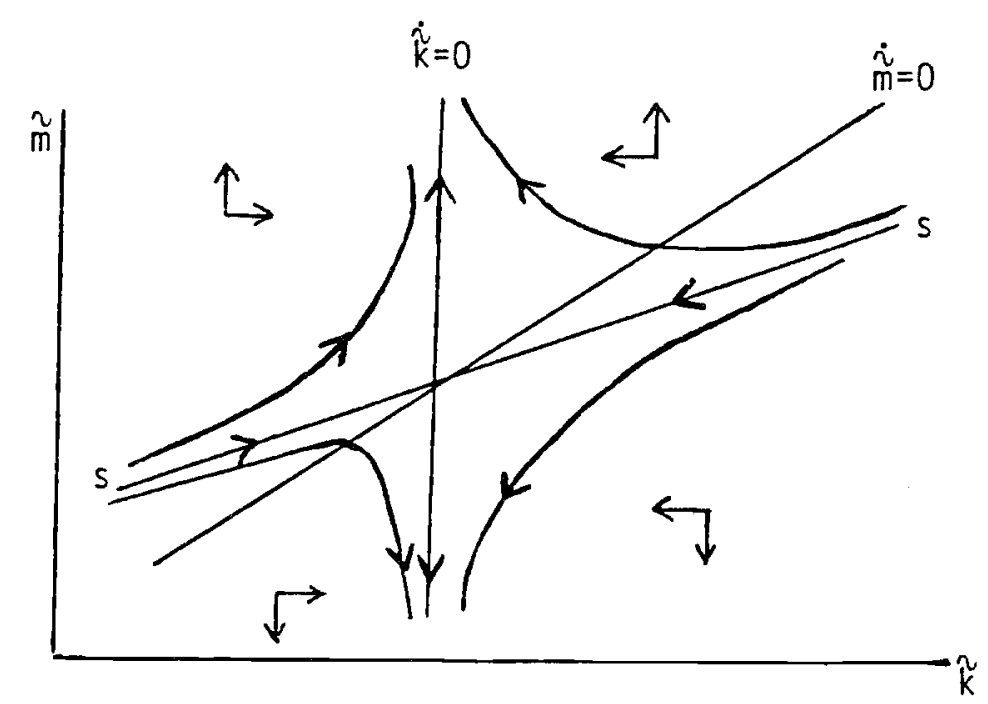

(b)
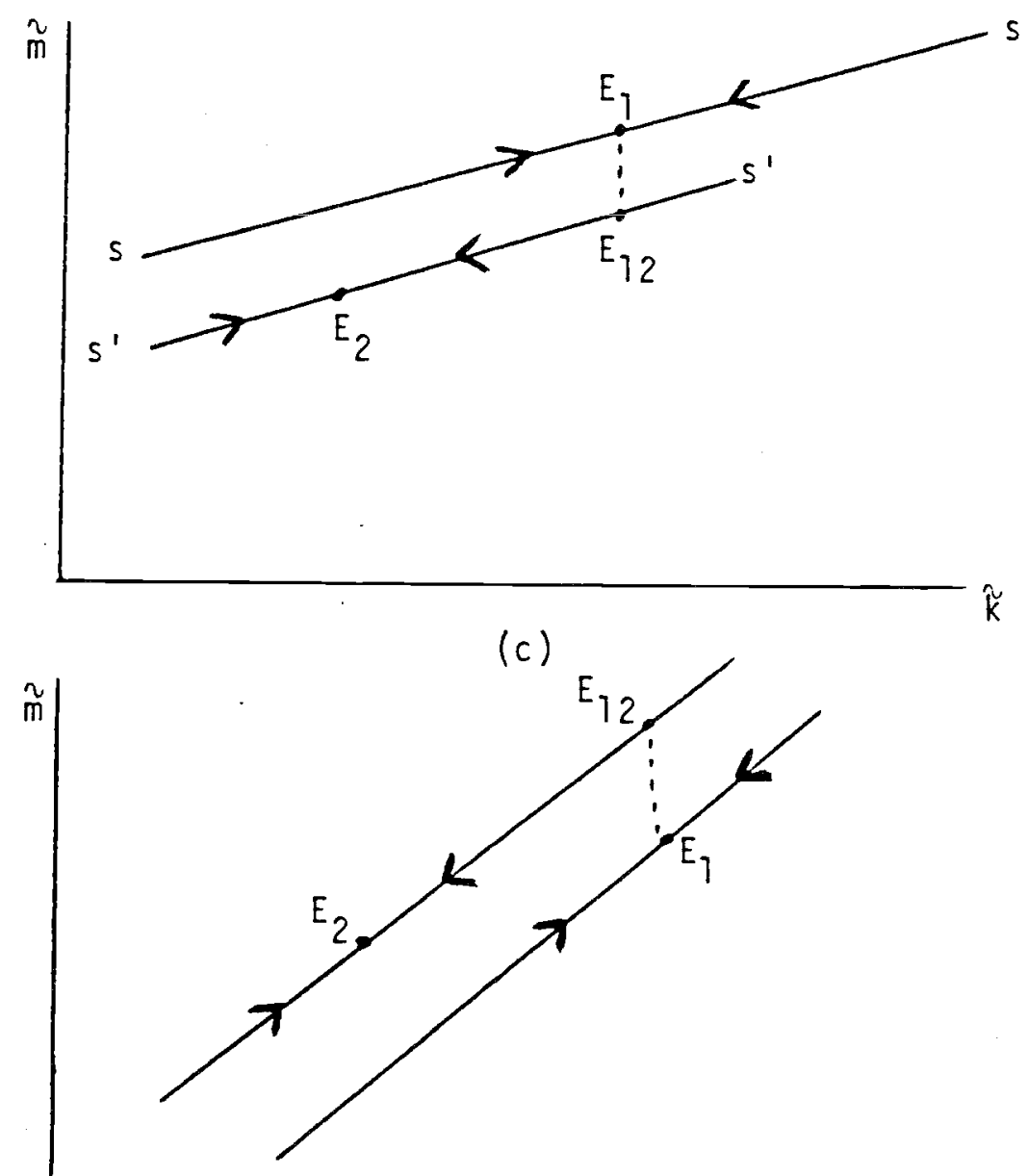
This money-capital model is the only well-known simnle monetary model to always have larger deficits associated with lower inflation in the long-run. The Sidrauski model analysed next exhibits some ambiguity in the deficit-infiation relation for the general case. A standard restriction, however, results in deficits and inflation being positively related in the long-run.

The Sidrauski model

Consider the rational expectations version of Sidrauski's model of money and growth (Sidrauski 1967) summarised in equations (17a) - (17e).

$$
\{\tilde{c}(t), \tilde{m}(t), \tilde{k}(t)\} \int_{0}^{\infty} u(\tilde{c}(t), \tilde{m}(t)) e^{-\delta t} d t
$$

subject to

$$
\tilde{m}+\tilde{k}=\tilde{a}
$$

(n)

7c) $\quad \dot{\tilde{a}}(t)=w(t)+r(t) \tilde{k}(t)-\tilde{\tau}(t)-\tilde{c}(t)-\frac{\dot{p}(t)}{p(t)} \tilde{m}(t)-n \tilde{a}(t)$.

$$
\tilde{c}(t), \tilde{m}(t), \tilde{k}(t) \geq 0
$$

The economy-wide constraints are:

$$
w=f(\tilde{k})-\tilde{k} f^{\prime}(\tilde{k})
$$

$$
\begin{aligned}
& r=f^{\prime}(\tilde{k}) \\
& \dot{\tilde{k}}=f(\tilde{k})-\tilde{g}-\tilde{c}-n \tilde{k} \\
& \dot{\tilde{m}}=\tilde{g}-\tilde{\tau}-\left(\frac{p}{p}+n\right) \tilde{m} \\
& \tilde{g}(t) \geqslant 0
\end{aligned}
$$

$\tilde{c}$ is per-capita consumption, ã real per-capita non-human private wealth, $\delta>0$ the subjective discount rate, $w$ the wage rate, $r$ the rate of return on capital. Public spending neither adds to the economy's productive capacity 
$-13-$

nor yields intrinsically valued consumption services. The production function $f(\tilde{k})$ is characterised by $f^{\prime}>0$ and $f^{\prime \prime}<0$ and satisfies the INADA conditions. The instantaneous utility function $u$ is strictly concave, twice continuously differentiable and increasing in $c$ and $m$. We also assume that $\lim _{c \rightarrow 0} u_{c}(\tilde{c}, \tilde{m})=$ $\lim _{m \rightarrow 0} \dot{u}_{m}(\tilde{c}, \tilde{m})=\infty$.

The first-order conditions for an interior optimum are given by the constraints $(17 b),(17 c)$ and, after substituting from (17d) and (17e), the marginal conditions $(18 a),(18 b)$ and $(18 c)$.

(18a)

$$
u_{m}(\tilde{c}(t), \tilde{m}(t))-u_{c}(\tilde{c}(t), \tilde{m}(t))\left(\frac{\dot{p}(t)}{p(t)}+f^{\prime}(\tilde{k}(t))\right)=0
$$

$$
u_{c}(\tilde{c}(t), \tilde{m}(t))\left(f^{\prime}(\tilde{k}(t))-n-\delta\right)+u_{c c}(\tilde{c}(t), \tilde{m}(t)) \dot{\tilde{c}}(t)+u_{c m}(\tilde{c}(t), \tilde{m}(t)) \dot{\tilde{m}}(t)=0
$$

(18c) $\quad \lim _{t \rightarrow \infty} u_{c}(\tilde{c}(t), \tilde{m}(t)) e^{-\delta t}=0$

To determine the long-run effect on the rate of inflation of an increase in the (real per-capita) government deficit we differentiate the steady-state conditions $(19 a)-(19 d)$ with respect to $\tilde{g}$ or $\tilde{\tau}$.

(19a) $\quad f^{\prime}(\tilde{k})=n+\delta$

(19b) $\quad f(\tilde{k})=\tilde{g}+\tilde{c}+n \tilde{k}$

(19c) $\quad u_{m}(\tilde{c}, \tilde{m})=u_{c}(\tilde{c}, \tilde{m})\left(\frac{\dot{p}}{p}+f^{\prime}(\tilde{k})\right)$

(19d) $\quad \frac{\dot{p}}{p}=\frac{\tilde{g}-\tilde{\tau}}{\tilde{m}}-n$ 
The steady-state capital-labour ratio is determined by equation (19a) and is independent of either the level of public spending or of the level of taxes." Per-capita private consumption is independent of the level of taxes but decreases one-for-one when public spending increases. The Sidrauski model has the usual property that, across steady states, an $x$ percentage point increase in the rate of growth of the nominal money stock will be associated with an $x$ percentage point higher rate of inflation. A larger deficit, however, does not necessarily entail a higher (steady state) proportional rate of growth of money, even in the very classical Sidrauski model.

The effects of higher spending and lower taxes on long-run inflation are given in equations $(20 a)-(20 b)$.

(20a)

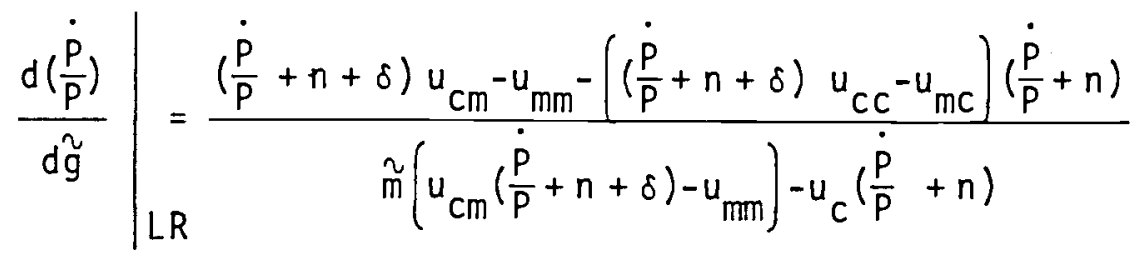

(20b)

$$
\frac{d\left(\frac{\dot{p}}{p}\right)}{d(-\tau)}=\frac{\left(n+\delta+\frac{\dot{p}}{p}\right) u_{c m}-u_{m m}}{\tilde{m}\left(u_{c m}\left(\frac{\dot{p}}{p}+n+\delta\right)-u_{m m}\right)-u_{c}\left(\frac{\dot{p}}{p}+n\right)}
$$

* If taxes were non-lump sum e.g. a tax on capital income at a proportional rate $\theta,(18 a),(18 b),(17 e)$ and $(17 g)$ would become

$\left(18 a^{\prime}\right) \quad u_{m}-u_{c}\left(\frac{\dot{p}}{p}+(1-\theta) f^{\prime}\right)=0$

$\left(18 b^{\prime}\right) \quad u_{c}\left((1-\theta) f^{\prime}-n-\delta\right)+u_{c c} \dot{i}+u_{c m} \dot{i}=0$

$\left(17 e^{\prime}\right) \quad r=(1-\theta) f^{\prime}(\tilde{k})$

$\left(17 g^{\prime}\right) \quad \dot{\tilde{m}}=\tilde{g}-\theta f^{\prime}(\tilde{k}) \tilde{k}-\left(\frac{\dot{p}}{p}+n\right) \tilde{m}$

In the long-run $(1-\theta) f^{\prime}(\tilde{k})=n+\delta$. An increase in $\theta$ now lowers steady state $\tilde{k}$. 
Also

(20c) $\left.\quad \frac{d \tilde{m}}{d \tilde{g}}\right|_{L R}=\frac{\tilde{m}\left(u_{c c}\left(\frac{\dot{p}}{p}+n+\delta\right)-u_{m c}\right)-u_{c}}{\tilde{m}\left(u_{c m}\left(\frac{\dot{p}}{p}+n+\delta\right)-u_{m m}\right)-u_{c}\left(\frac{\dot{p}}{p}+n\right)}$

and

$(20 d)$

$$
\left.\frac{d \tilde{m}}{d(-\tilde{\tau})}\right|_{L R}=\frac{-u_{c}}{\tilde{m}\left(u_{c m}\left(\frac{\dot{p}}{p}+n+\delta\right)-u_{m m}\right)-u_{c}\left(\frac{\dot{p}}{p}+n\right)}
$$

The signs of all these steady-state multipliers are indeterminate. Even the imposition of the stability or convergence conditions for the unrestricted system, given in equations (21) - (23), does not suffice to determine the signs of the long-run multipliers.

$$
\dot{\tilde{k}}=f(\tilde{k})-\tilde{g}-\tilde{c}-n \tilde{k}
$$

$$
\dot{\tilde{c}}=-\frac{u_{c}(\tilde{c}, \tilde{m})}{u_{c c}(\tilde{c}, \tilde{m})}(f(\tilde{k})-n-\delta)-\frac{u_{c m}(\tilde{c}, \tilde{m})}{u_{c c}(\tilde{c}, \tilde{m})}\left[\tilde{g}-\tilde{\tau}-\left(\frac{u_{m}(\tilde{c}, \tilde{m})}{u_{c}(\tilde{c}, \tilde{m})}-f^{\prime}(\tilde{k})+n\right) \tilde{m}\right]
$$

$$
\dot{\tilde{m}}=\tilde{g}-\tilde{\tau}-\left(\frac{u_{m}(\tilde{c}, \tilde{m})}{u_{c}(\tilde{c}, \tilde{m})}-f^{\prime}(\tilde{k})+n\right) \tilde{m}
$$

The assumption that the instantaneous utility function is separable $\left(u_{\mathrm{cm}}=0\right)$ simplifies the algebra and helps resolve the ambiguities

(24a) $\left.\frac{d\left(\frac{\dot{p}}{p}\right)}{d \tilde{g}}\right|_{L R}=\frac{u_{m m}+\left(\frac{\dot{p}}{p}+n+\delta\right) u_{c c}\left(\frac{\dot{p}}{p}+n\right)}{\tilde{m u}_{m m}+u_{c}\left(\frac{\dot{p}}{p}+n\right)}$ 
$(24 b)$

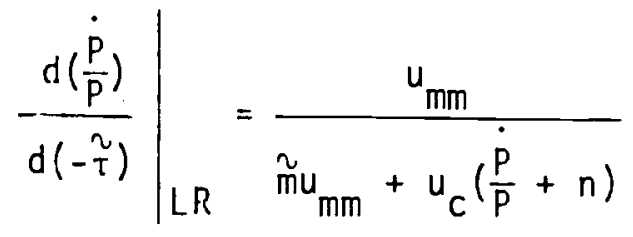

(25a) $\left.\frac{d \tilde{m}}{d \tilde{g}}\right|_{L R}=\frac{u_{c}-\tilde{m} u_{c c}\left(\frac{\dot{p}}{p}+n+\delta\right)}{\tilde{m} u_{m m}+u_{c}\left(\frac{\dot{p}}{p}+n\right)}$

$(25 b)$

$$
\left.\frac{d \tilde{m}}{d(-\tilde{\tau})}\right|_{L R}=\frac{u_{c}}{\tilde{m} u_{m m}+u_{c}\left(\frac{\dot{p}}{p}+n\right)}
$$

The state-space representation of the model when $u_{\mathrm{cm}}=0$ given in equations (26), (27) and (28)

$$
\dot{\tilde{c}}=-\frac{u_{c}(\tilde{c}, \tilde{m})}{u_{c c}(\tilde{c}, \tilde{m})}\left(f^{\prime}(\tilde{k})-n-\delta\right)
$$

$$
\begin{aligned}
& \dot{\tilde{k}}=f(\tilde{k})-\tilde{g}-\tilde{c}-n \tilde{k} \\
& \dot{\tilde{m}}=\tilde{g}-\tilde{\tau}-\left(\frac{u_{m}(\tilde{c}, \tilde{m})}{u_{c}(\tilde{c}, \tilde{m})}-f^{\prime}(\tilde{k})+n\right) \tilde{m} .
\end{aligned}
$$

As a further simplifying assumption we shall assume that the partial coefficient of absolute risk aversion $-\frac{u_{c c}}{u_{c}}=\frac{1}{\rho}$ is a positive constant, i.e. (26) becomes

$$
\left(26^{\prime}\right) \quad \dot{\tilde{c}}=\rho\left(f^{\prime \prime}(k)-n-\delta\right) \quad \rho>0
$$

Without this assumption the analysis that follows (and Figure 2) are valid only in the neighbourhood of a stationary equilibrium. Equations (26') and (27) jointly determine the behaviour of $\tilde{z}$ and $\tilde{k}$, independently of $\tilde{m}$. Given 
FIGURE 2

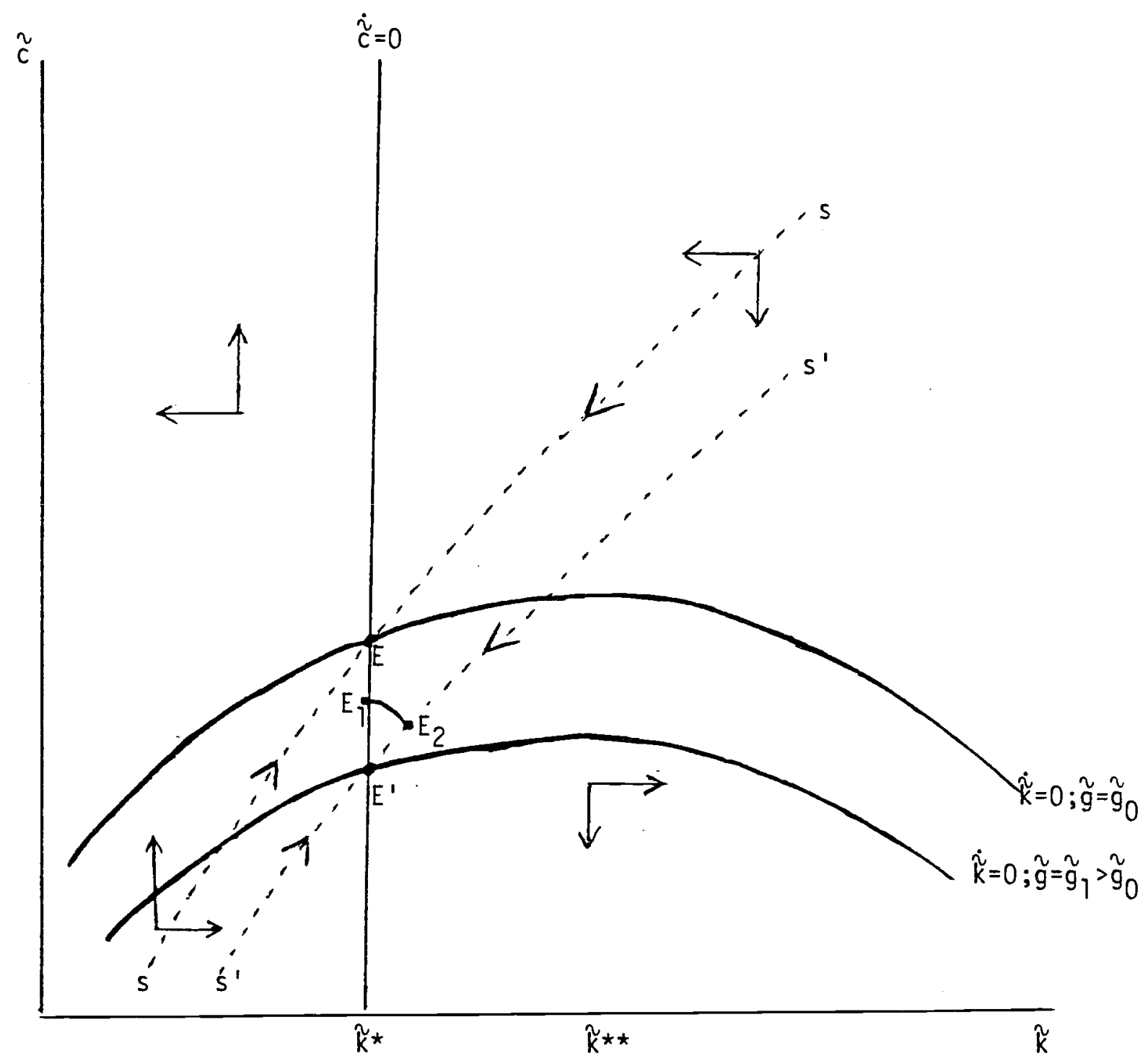


the solutions for $\tilde{c}$ and $\tilde{k}$, equation (28) determines the behaviour of $\tilde{m}$.

The dynamics of $\tilde{c}$ and $\tilde{k}$ are illustrated in Figure 2. The $\dot{\tilde{c}}=0$ locus is vertical at $\tilde{k}^{*}$, defined by $f^{\prime}\left(\tilde{k}^{\star}\right)=n+\delta$. The $\dot{\tilde{k}}=0$ locus is strictly concave, slopes upward for $\tilde{k}<\tilde{k}^{\star \star}$, reaches a maximum at $\tilde{k}=\tilde{k}^{\star \star}$ and slopes downward for $\tilde{k}>\tilde{k}^{\star \star}$ where $k^{\star \star}$ is defined by $f^{\prime}\left(k^{\star \star}\right)=n$. Since $\delta>0$ and $f^{\prime \prime}<0, \tilde{k}^{\star \star}>\tilde{k}^{\star}$. The stationary equilibrium at $E$ is a saddlepoint. $\tilde{k}$ is a predetermined variable, $\tilde{c}$ a non-predetermined variable. The unique convergent saddlepath is SS. Starting from an initial equilibrium at $E$, a cut in taxes, $\tilde{\tau}$, (whether anticipated or unanticipated), will have no effect, short-run or long-run, on $\tilde{k}$ and $\tilde{c}$.

An unanticipated increase in public spending by an amount dg will immediately depress consumption by the same amount as the increase in public spending. The $\dot{\tilde{k}}=0$ locus shifts down vertically by an amount equal to $\mathrm{dg}$. The system remains at $E^{\prime}$ afterwards. An anticipated (at $t=t_{0}$ ) increase in public spending (at $t=t_{1}>t_{0}$ ) leads to a smaller immediate drop in consumption, to $E_{1}$, say. The jump in consumption at $t_{0}$ places the system on the divergent trajectory (drawn with reference to $E$, that will put they system on the unique convergent trajectory through $E^{\prime}$ at $t_{p}$, the moment the increase in public spending actually takes place. In Figure 2 that point is $E_{2}$. The path of consumption therefore only has a discontinuity at $t=t_{0}$, the moment that "news" arrives. Anticipated future jumps in private consumption are never optimal. Note that after the initial downward jump in $c$, at $t=t_{0}$, consumption continues to decline gradually along $E_{1}-E_{2}-E^{\prime}$. Capital is first accumulated (along $E_{1}-E_{2}$ ) and then decumulated (along $E_{2}-E^{\prime}$ ).

The characteristic equation of the system (26'), (27) and (28) linearised around a stationary equilibrium is 


$$
-\left\{\left\{\frac{u_{m}}{u_{c}}-f^{\prime}+n\right\}+\tilde{m} \frac{u_{m m}}{u_{c}}+\lambda\right\}\left\{\lambda^{2}-\lambda\left(f^{\prime}-n\right)+o f^{\prime \prime}\right\}=0
$$

The characteristic roots of the $\tilde{k}-\tilde{c}$ subsystem are found by factoring $\lambda^{2}-\lambda\left(f^{\prime}-n\right)+\rho f^{\prime \prime}=0$. It is clear that the $\tilde{k}-\tilde{c}$ subsystem has one stable and one unstable characteristic root. This describes the saddlepoint equilibrium in a neighbourhood of $E$. The three characteristic roots are

$$
\lambda_{1}=\frac{f^{\prime}-n-\sqrt{\left(f^{\prime}-n\right)^{2}-4 \rho f^{\prime \prime}}}{2}<0
$$

$$
\lambda_{2}=\frac{f^{\prime}-n+\sqrt{\left(f^{\prime}-n\right)^{2}-4 p f^{\prime \prime}}}{2}>0
$$

$$
\lambda_{3}=f^{\prime}-n-\frac{u_{m}}{u_{c}}-\tilde{m} \frac{u_{m m}}{u_{c}}
$$

The real stock of money balances is a non-predetermined variable. The existence of a unique convergent solution trajectory therefore requires that $\lambda_{3}$ be positive. We now investigate whether $\lambda_{3}>0$ is sufficient to ensure that $\frac{d\left(\frac{\dot{p}}{p}\right)}{d \tilde{g}}$ and $\frac{d\left(\frac{\dot{p}}{p}\right)}{d(-\tilde{\tau})}$ are positive.

The condition that $\lambda_{3}$ be positive is equivalent to the condition that the denominator of $(24 a),(24 b)$ and $(25 a),(25 b)$ be negative. Given this it is clear from (24b) that, with separability, a larger real per-capita deficit due to lower taxes will be associated with a higher rate of inflation and (from(25b)) a lower real per-capita stock of money balances. 
The effect on long-run inflation of larger deficits due to increased public spending is not quite unambiguous even with $u_{\mathrm{cm}}=0$. A sufficient condition for higher inflation to result from higher spending is, from (24a) that the initial rate of inflation is non-negative.

The behaviour of $\tilde{m}$ after an unanticipated permanent shock is given by

$$
\tilde{m}(t)-\bar{m}=\left(\lambda_{1}-\lambda_{3}\right)^{-1} \bar{m}\left(f^{\prime \prime}+\frac{u_{m}}{\left(u_{c}\right)^{2}} u_{c c} \lambda_{2}\right)(\tilde{k}(t)-\bar{k})
$$

$\bar{m}$ and $\bar{k}$ are the new steady values of $\tilde{m}$ and $\tilde{k}$ respectively. Since $\tilde{k}$ doesn't change after an unanticipated change in $\tilde{g}$ or $\tilde{\tau}$, $\tilde{m}$ jumps immediately to its new equilibrium value. From (25a) and (25b) we know that a larger value of $\tilde{g}$ and a lower value of $\tilde{\tau}$ are associated with a lower long-run value of $\tilde{m}$, i.e. with a higher velocity. The impact effect on the price level is therefore an immediate jump up. The rate of inflation also immediately assumes its new equilibrium value. Since $\frac{\dot{p}}{p}=(\tilde{g}-\tilde{\tau}) \tilde{m}^{-1}-n$, the rate of inflation will be higher both because $\tilde{g}-\tilde{\tau}$ is larger and because $\tilde{m}$ is smaller. 
$-21-$

$\frac{\text { 3. DEFICITS, INFLATION AND CROWDING OUT IN }}{\text { CLOSED ECONOMIES WITH GOVERNMENT BONDS }}$

(Ba) The model of Sargent and Wallace

A convenient starting point for the analysis of the relationship between deficits, competition for real resource flows between the private and public sectors and monetary growth is the model of Sargent and wallace (1981), " of which the continuous time analogue is given in equations $31-40$. All interestbearing government debt, $B$, has a fixed nominal market value and a variable nominal interest rate, $i$. L denotes the size of population and labour force, $n$ its growth rate

$$
\frac{\dot{M}(t)+\dot{B}(t)}{P(t)} \equiv D(t)+i(t) \frac{B(t)}{P(t)}
$$

$$
D(t) \equiv G(t)-T(t)
$$

$$
\begin{aligned}
& \frac{M(t)}{P(t) L(t)}=\gamma_{1}-\gamma_{2} \frac{\dot{p}(t)}{P(t)} \quad \gamma_{1} \geqslant 0 ; \gamma_{2} \geqslant 0 \\
& i(t)=r(t)+\frac{\hat{p}(t)}{p(t)}
\end{aligned}
$$$$
r(t)=\bar{r}
$$

$$
\dot{L}(t) / L(t)=n
$$

$$
\begin{aligned}
& \frac{d}{d t}\left(K(t)+\frac{B(t)}{P(t)}\right)=n\left(K(t)+\frac{B(t)}{P(t)}\right) \\
& K(t) \geqslant 0 ; \quad\left(K(0)+\frac{B(0)}{P(0)}\right)=\bar{W}
\end{aligned}
$$

(38a) $\bar{r}>n$

(38b) $\quad \bar{r}>-\frac{\dot{p}(t)}{p(t)}$

$$
\dot{M}(t) / M(t)=\theta \quad 0 \leqslant t<\bar{t}
$$

(40) $\quad \frac{B(t)}{P(t) L(t)}=\frac{B(\bar{t})}{P(\bar{t}) L(\bar{t})} \quad t \geqslant \bar{t}$ 
Output, employment and the real value of the stock of bonds plus the capital stock grow at the same proportional rate, $n$. The real interest rate is fixed. The model exhibits one-for-one crowding out of private capital formation by changes in the real stock of government bonds, at a given real interest rate. The demand for real per-capita money balances is a non-increasing function of the expected rate of inflation. (38a, b) pre technical but not entirely innocuous assumptions. The model has some peculiar features. One class of agents (the poor) hold only money as a store of value. A second class of agents (the rich) hold the bonds and real capital. As long as (38b) holds they will not hold any money. This accounts for the absence of real money balances in (37) and the dependence of money demand on the rate of inflation rather than the nominal interest rate. Bonds and real capital are perfect substitutes in the portfolios of (rich) private agents.

Equations (39) and (40) describe the financial rule followed by the government, i.e. its money vs. bonds financing mix for a given path of $D(t) \equiv G(t)-T(t)$. The rate of growth of the money stock is $\theta$ up to $t=\bar{t}$. The amount of bond-financing for $t<\bar{t}$ is therefore residualiy determined by the budgetconstraint, $D(t)$ and the monetary growth rate. After $t=\bar{t}$ the authorities following a bond financing rule that keeps the real per-capita stock of bonds constant at the level achieved at $\bar{t}$, i.e.

$$
\dot{B}(t)=\left(\frac{\dot{p}}{p}+n\right) B(\bar{t}) \text { for } t>\bar{t}
$$

From time $\bar{t}$ onwards, growth of the money stock is therefore residually determined by the budget constraint, $D(t)$ and the bond-financing rute (47).

Assuming rational expectations, equations (31), (34) and (41) imply for $t \geqslant \bar{t}$

$$
\frac{\dot{M}(t)}{P(t) L(t)} \equiv \frac{G(t)-T(t)}{L(t)}+(\bar{r}-n) \frac{B(\bar{t})}{P(\bar{t}) L(\bar{t})}
$$


or

$$
\frac{\dot{M}(t)}{M(t)}=\frac{P(t) L(t)}{M(t)}\left[\frac{G(t)-T(t)}{L(t)}+(\bar{r}-n) \frac{B(\bar{t})}{P(\bar{t}) L(\bar{t})}\right] \quad t \geqslant \bar{t}
$$

Consider first the case where the demand for money is independent of the expected rate of inflation, i.e. $\gamma_{2}=0$. In that case

$$
\frac{\dot{P}(t)}{P(t)}=\frac{\dot{M}(t)}{M(t)}-n=\frac{1}{r_{1}}\left[\frac{G(t)-T(t)}{L(t)}+(\bar{r}-n) \frac{B(\bar{t})}{P(\bar{t}) L(\bar{t})}\right]-n \quad t \geqslant \bar{t}
$$

Note that the deficit measure relevant for monetary growth and thus for inflation in periods beyond $\bar{t}$ is

$$
D^{*}=\frac{G(t)-T(t)}{L(t)}+(\bar{r}-n) \frac{B(\bar{t})}{P(\bar{t}) L(\bar{t})}
$$

The conventionally defined real per-capita deficit is

$\left(44^{\prime}\right)$

$$
D^{\star *}=\frac{G(t)-T(t)}{L(t)}+\left(\bar{r}+\frac{\dot{P}}{P}\right) \frac{B(\bar{t})}{P(\bar{t}) L(\bar{t})}
$$

The intuition behind (44) is clear. Government spending has to be financed either by explicit taxes, by borrowing or by printing money. To the extent that borrowing increases the real stock of per-capita government bonds held by private agents, it increases the future real per-capita deficit (if the real interest rate exceeds the natural rate of growth). If there is a finite upper bound on the stock of real per-capita bonds that the private sector will hold, (or the public sector is willing to owe) then once that upper bound is reached, further deficits have to be financed by money creation. The point to note is that only nominal bond issues in excess of the rate of inflation plus the natural rate of growth times the outstanding stock of bonds $\left(\dot{B}-\left(\frac{\dot{p}}{p}+n\right) B\right)$ will raise the real per-capita stock of bonds. In the flow-of-funds accounts, of which the government budget constraint is part, debt service is recorded (in real terms) as $\frac{i B}{P}$. Inflation 
erodes the real value of the outstanding stock of bonds by $\frac{P}{P} \frac{B}{P}$ and population growth means that ceteris paribus bond demand grows by $n \frac{B}{p}$. Bond issues less than $\left(\frac{\dot{p}}{p}+n\right) B$ are associated with a falling stock of real per-capita government interest-bearing debt, lower future conventionally measured deficits if $r>n$ and, ceteris paribus lower future money creation.

Note also that $\dot{B}<\left(\frac{\dot{P}}{P}+n\right) B$ means that/there is per-capita "crowding in" in the Sargent-Wallace model. From equation (29) it can be seen that real bonds (changes in the real stock of bonds) "crowd out" real capital (real capital formation) on a one-for-one basis. The total rate of accumulation of capital-cum-real bonds is exogenously given and grows at the natural rate $n$. Crowding out takes place not through changes in the real interest rate, which is constant by assumption, but by channelling private savings into public debt rather than private capital at a given real interest rate.

Deficits are a source of concern to policy makers because (a) to the extent that they are not monetised they are feared to cause crowding out and (b) to the extent they are monetised they are feared to cause inflation. To investigate whether deficits cause crowding out we consider the behaviour of the real stock of government interest-bearing debt (or the real per-capita stock of government interest-bearing debt) for a given path of exhaustive spending $G(t)$ and taxes net of transfers $T(t)$ and for a given path of monetary growth. This corresponds to the behaviour of the Sargent-Wallace model for $t<\bar{t}$. To determine what the monetary growth rate implied by the fiscal stance is, we look at the behaviour of monetary growth for given paths of $G(t)$ and $T(t)$ and for a given value of the real stock of government debt or the real stock of government debt per-capita. This corresponds to the behaviour of the Sargent-Wallace model for $t \geqslant \bar{t}$.

In the Sargent-Wallace model changes in $\frac{B}{P}$ crowd out private capital onefor-one. This extreme form of crowding out will not hold in many more plausible 
models. It seems safe to say, however, that in any model not exhibiting non-Ricardian debt neutrality, the change in the real (or real per-capita) stock of public sector interest-bearing debt will be the proximate determinant and the best single indicator of the change in the degree of aggregate or per capita crowding out pressure that the government is bringing to bear on the economy. The proposed crowding out measures are given in $(45 \mathrm{a}, \mathrm{b})$

$$
\begin{aligned}
& \frac{d}{d t}\left(\frac{B(t)}{P(t)}\right)=G(t)-T(t)+\bar{r} \frac{B(t)}{P(t)}-\theta(t) \frac{M(t)}{P(t)} \text { (aggregate crowding out) } \\
& \frac{d}{d t}\left(\frac{B(t)}{L(t) P(t)}\right)=\frac{G(t)-T(t)}{L(t)}+(\bar{r}-n) \frac{B(t)}{L(t) P(t)}-\theta(t) \frac{M(t)}{P(t) L(t)}
\end{aligned}
$$

(per-capita crowding out)

Equation (45b) represents the behaviour of the real per-capita stock of bonds for $t<\bar{t}$ in the Sargent-Wallace model if $\theta(t)=\theta$.

The eventual monetisation implied by the deficit is given by (46a) or (46b)

$$
\begin{aligned}
\frac{\dot{M}(t)}{M(t)} & =V(t)\left(\frac{G(t)-T(t)}{Y(t)}+\bar{r} \frac{B(t)}{P(t) Y(t)}\right)=\frac{1}{r_{1}}\left(\frac{G(t)-T(t)}{L(t)}+\bar{r} \frac{B(t)}{P(t) L(t)}\right) \\
\frac{\dot{M}(t)}{M(t)} & =V(t)\left(\frac{G(t)-T(t)}{Y(t)}+(\bar{r}-n) \frac{B(t)}{P(t) Y(t)}\right) \\
& =\frac{1}{r_{1}}\left(\frac{G(t)-T(t)}{L(t)}+(\bar{r}-n) \frac{B(t)}{P(t) L(t)}\right)
\end{aligned}
$$

Equation (46a) determines monetary growth on the assumption of no change in aggregate crowding out while $(46 \mathrm{~b})$ assumes no change in per-capita crowding out. Equation (46b) represents monetary growth in the Sargent-Wallace model for $t \geq \bar{t} . \quad V$ again denotes the income velocity of circulation of money $V \equiv \frac{P Y}{M}$. If output or income $Y$ grows at the same rate as population; if, as in the Sargent-Wallace model, $Y=L$ by choice of units and if $\gamma_{2}=0$, then $V=\frac{1}{\gamma_{1}}$. The degree of aggregate or per-capita crowding out depends on the amount of money 
financing that is permitted. A useful benchmark is e.g. a monetary growth rate consistent (in the long run) with zero inflation: $\theta=n$. Given any rule for monetary growth, the aggregate and per-capita crowding out implied by the fiscal stance can be found from (45a) and (45b). The per capita crowding out equation (45b) is the proper one for the evaluation of the very long run or steady state implications of the fiscal stance for crowding out since in the steady state $\frac{B}{P L}$ must be constant. In (45b), the conventionally measured deficit is corrected not only for the effects of inflation and real growth on the outstanding real per-capita stock of bonds (and on the demand for bonds by private agents) but also for any monetisation permitted by the authorities. It is obvious that in any given period in which the conventionally measured deficit is large because of a high current rate of inflation and high nominal interest rates, the inflation-and-growth-corrected deficit may well be significantly smaller: the deficit is a monetary phenomenon; its elimination requires a monetary, not a fiscal, correction.

Similar conclusions can be drawn as regards the implications of the fiscal stance and the conventionally measured deficit for monetary growth in the long run. Equations (46a) and (46b) show what the spending and tax programmes imply for monetary growth if bond financing is conducted in such a way as to neither raise nor reduce the crowding out pressure (aggregate or per-capita) exercised by the government.

The real (per-capita) stock of bonds that the authorities (39) aim to keep constant need not be the historically inherited one. It could be a target stock to be achieved at some future date. The deficit measure relevant for eventual monetisation is the conventionally measured deficit corrected for the effect of inflation on the real value of the outstanding stock of bonds and (in the case of $(46 b)$ ) for the effect of real growth. Current high inflation may make the current deficit (and the current deficit-GNP ratio) high because 
of its effect on nominal interest rates. If the inflation-corrected deficit is nevertheless negative, this means that, if the authorities were to stick to their spending and taxation programmes (as a proportion of GNP) and if they were to keep the degree of aggregate crowding out $\left(\frac{B}{p}\right)$ constant, they would henceforth have a negative rate of monetary growth and therefore, in due course, a negative rate of inflation. In other words, an inflation-and-growthcorrected budget surplus means that, whatever the current conventionally measured deficit may be (i.e. regardless of the current inflation premium in nominal interest rates), a negative rate of monetary growth would result if the government simply froze its spending and taxation programme as a proportion of GNP and used bond-financing to keep the bond-(trend)GNP ratio constant. (3b) Does tighter money now mean higher inflation in the future?

Sargent and Wallace obtained the prima facie paradoxical result that tighter money early on (a lower value of $\theta$ for $t<\bar{t}$ ) may imply a higher rate of growth of money (and a higher rate of inflation) later on (for $t \geqslant \bar{t}$ ). Specifically, when $\gamma_{2}=0$, a lower value of $\theta$ (and thus a lower rate of inflation) for $t<\bar{t}$ always implies a higher rate of growth of money (and thus a higher rate of inflation) for $t \geqslant \bar{t}$. Below I argue that when $\gamma_{2}>0$ a lower value of $\theta$ for $t<\bar{t}$ need not necessarily imply a higher rate of growth of the money supply for $t \geqslant \bar{t}$. When it does however, it is possible that a lower value of $\theta$ for $t<\bar{t}$ implies a higher rate of inflation not only for $t \geqslant \bar{t}$ but also for $t<\bar{t}$. Current inflation, when $\gamma_{2} \neq 0$, depends on the entire anticipated future path of the money supply. The higher later rates of money growth may, for certain parameter configurations, dominate the lower earlier rates of growth of money as regards their effect on the price level and the rate of inflation for $t<\bar{t}$.

Consider first the case where $\gamma_{2}=0$. From (43), the rate of inflation will be higher in each period beyond $t$, the higher $\frac{B(\bar{t})}{P(\bar{t}) L(\bar{t})}$, if $\bar{r}>n$, since 
(47)

$$
\frac{\partial \frac{\dot{P}(t)}{P(t)}}{\partial\left[\frac{B(\bar{t})}{P(\bar{t}) L(\bar{t})}\right]}=\frac{1}{\gamma_{1}}(\bar{r}-n)>0 \quad t \geqslant \bar{t}
$$

It is also easily checked that $\frac{B(\bar{t})}{P(\bar{t}) L(\bar{t})}$ will be higher, the lower $\theta$, the proportional rate of growth of the money stock, for $t<\bar{E}$. For $t<\bar{E}$, $\frac{\dot{P}}{\mathrm{P}}=\frac{\dot{M}}{M}-n=\theta-n$ and $\frac{M}{P L}=\gamma_{j}$. The budget constraint can therefore be written as:

$$
\frac{\dot{B}}{P L}=\frac{G-T}{L}-\theta \gamma_{1}+(\bar{r}+\theta-n) \frac{B}{P L} .
$$

Therefore,

$$
\frac{d}{d t}\left(\frac{B}{P L}\right)=\frac{G-T}{L}-\theta \gamma_{1}+(\bar{r}-n) \frac{B}{P L} \quad t<\bar{t}
$$

and

$$
\begin{gathered}
\frac{B(t)}{P(t) L(t)}=\frac{B(0)}{P(0) L(0)} e^{(\bar{r}-n) t}+\int_{0}^{t} e^{(\bar{r}-n)(t-s)}\left(\frac{G(s)-T(s)}{L(s)}-\theta \gamma_{7}\right) d s \\
t<\bar{t}
\end{gathered}
$$

With $\gamma_{2}=0, \frac{B(0)}{P(0) L(0)}$ is determined by the initial values of $B(0), L(0)$ and $M(0)$ and by (33).

Therefore,

$$
\frac{\partial}{\partial \theta}\left(\frac{B(\bar{t})}{P(\bar{t}) L(\bar{t})}\right)=-\gamma_{1} \int_{0}^{\bar{t}} e^{(\bar{r}-n)(\bar{t}-s)} d s<0
$$

Equations (47) and (49) together imply that tighter money now (which with $\gamma_{2}=0$ means lower inflation now) means looser money and higher inflation later, if there are no changes in the spending, tax and transfer programmes. 
When we consider the more general case in which the demand for money is a decreasing function of the expected rate of inflation $\left(\gamma_{2}>0\right.$ in equation (33)) the analysis becomes quite a bit more involved. It is still the case that

$$
\frac{\dot{M}(t)}{M(t)}=\frac{P(t) L(t)}{M(t)}\left(\frac{G(t)-T(t)}{L(t)}+(\bar{r}-n) \frac{B(\bar{t})}{P(\bar{t}) L(\bar{t})}\right) \quad t \geqslant \bar{t}
$$

The price level is now, however, a "forward-looking" variable whose value is given by

$$
P(t)=\frac{1}{\gamma_{2}} \int_{t}^{\infty} e^{\frac{\gamma_{1}}{\gamma_{2}}(t-s)} \frac{\hat{M}(s, t)}{\hat{L}(s, t)} d s
$$

If $\frac{G(t)-T(t)}{L(t)} \equiv \delta(t)$ is constant for all $t \geqslant \vec{t}$, there exists a steady state solution from $\bar{t}$ onwards with $\frac{\dot{P}(t)}{P(t)}=\frac{\dot{M}(t)}{M(t)}-n$.

Therefore for $t \geqslant \bar{t}$

$$
\frac{\dot{p}}{p}=\frac{1}{\gamma_{1}-\gamma_{2} \frac{\dot{p}}{p}}\left(\delta+(\bar{r}-n) \frac{B(\bar{t})}{p(\bar{t}) L(\bar{t})}\right)-n
$$

This quadratic in $\frac{\dot{p}}{p}$ has two roots:

$$
\dot{p}=\frac{\gamma_{1}-n \gamma_{2} \pm \sqrt{\left(\gamma_{1}-n \gamma_{2}\right)^{2}-4 \gamma_{2}\left\{\delta+(\bar{r}-n) \frac{B}{P L}-n \gamma_{1}\right\}}}{2 \gamma_{2}}
$$

For this to make sense the roots should of course be real. In addition we also assume that the authorities will always choose the lower of the two inflation rates, $\pi$, i.e. that 
$\left(52^{\prime}\right)$

$$
\dot{p}=\pi=\frac{\gamma_{1}-n \gamma_{2}-\sqrt{\left(\gamma_{1}-n \gamma_{2}\right)^{2}-4 \gamma_{2}\left\{\delta+(\bar{r}-n) \frac{B}{P L}-n \gamma_{1}\right\}}}{2 \gamma_{2}}
$$

From (52') it follows that the inflation rate for $t \geqslant \bar{t}$ is again an increasing function of $\frac{B}{P L}$ since

$$
\frac{\partial \pi}{\partial\left(\frac{B}{P L}\right)}=(\bar{r}-n)\left[\left(\gamma_{1}-n \gamma_{2}\right)^{2}-4 \gamma_{2}\left\{\delta j+(\bar{r}-n) \frac{B}{P L}-n \gamma_{1}\right\}\right]^{-\frac{1}{2}}>0
$$

It no longer follows necessarily, however, that a lower value of $\theta$ for $t<\bar{t}$ implies a higher value of $\frac{B(\bar{t})}{P(\bar{t}) L(\bar{t})}$. Let $\frac{B(t)}{P(t) L(t)} \equiv b(t)$. For simplicity

we assume in what follows that bonds are index-linked. Jumps in $p$ will therefore not affect $b$.

Since

$$
\dot{b}(t)=\delta(t)+(\bar{r}-n) b(t)-\frac{\dot{M}(t)}{M(t)} \frac{M(t)}{P(t) L(t)}
$$

We have

$$
b(\bar{t})=b(0) e^{(\bar{r}-n) \bar{t}}+\int_{0}^{\bar{t}} e^{(\bar{r}-n)(\bar{t}-s)}\left[\delta(s)-\frac{\dot{M}(s)}{M(s)} \frac{M(s)}{P(s) L(s)}\right] d s
$$

Since $\frac{\dot{M}(s)}{M(s)}=\theta$ for $t<\bar{t}$, this becomes

$$
b(\bar{t})=b(0) e^{(\bar{r}-n) \bar{t}}+\int_{0}^{\bar{t}} e^{(\bar{r}-n)(\bar{t}-s)}\left[\delta(s)-\theta \frac{M(0)}{L(0)} e^{(\theta-n) s} \cdot \frac{\bar{T}}{P(s)}\right] d s
$$

From (50) we note that for $s \leq \bar{t}$,

$$
p(s)=\frac{1}{\gamma_{2}}\left[\int_{s}^{\bar{t}} e^{\frac{\gamma_{1}}{\gamma_{2}}(s-u)} \frac{M(0)}{L(0)} e^{(\theta-n) u} d u+\int_{\bar{t}}^{\infty} e^{\frac{\gamma_{1}}{\gamma_{2}}(s-u)} \frac{M(0)}{L(0)} e^{[(\theta-n) \bar{t}+\pi(u-\bar{t})]} d u\right]
$$


or

$$
p(s)=\frac{M(0)}{\gamma_{2} L(0)} e^{\frac{\gamma_{1}}{\gamma_{2}} s}\left[\int_{s} e^{\left(\theta-n-\frac{\gamma_{1}}{\gamma_{2}}\right) u} d u+e^{(\theta-n-\pi) \bar{t}} \int_{\bar{t}}^{\infty} e^{\left(\pi-\frac{\gamma_{1}}{\gamma_{2}}\right) u} d u\right]
$$

Therefore, noting from $\left(52^{\prime}\right)$ that $\pi$ is an (increasing) function of $b(\bar{t})$, we have:

$$
\frac{\partial b(\bar{t})}{\partial \theta}=-\frac{M(0)}{L(0)} e^{(\bar{r}-n) \bar{t}} \int_{0}^{\bar{t}} e^{(\theta-\bar{r}) s} \frac{1}{\bar{P}(s)}\left[1-\frac{\theta}{P(s)} \frac{\partial P(s)}{\partial \theta}+\theta s\right] d s
$$

and

$$
\begin{aligned}
& \frac{\partial P(s)}{\partial \theta}=
\end{aligned}
$$

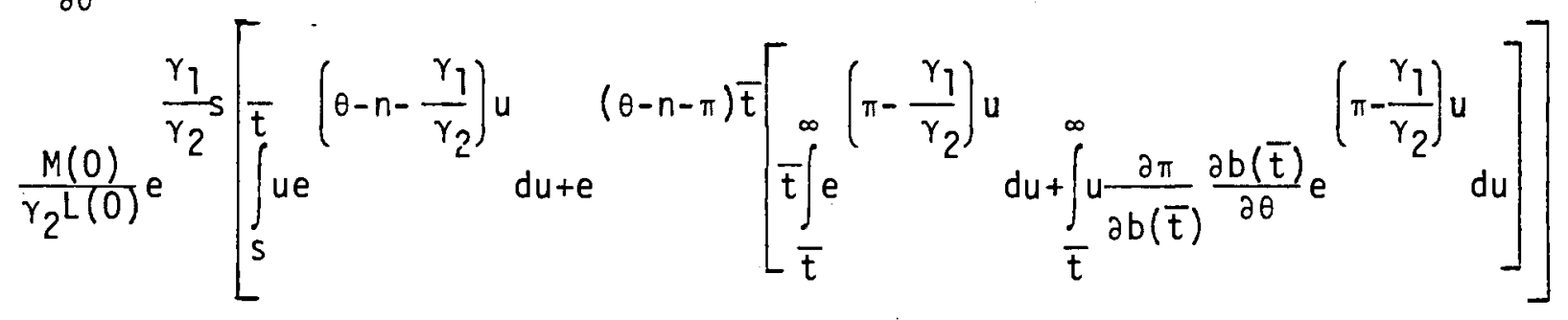

Equations $(57)$ and $(58)$ can be solved jointly for $\frac{\partial b(\bar{t})}{\partial \theta}$. The resulting implicit equation for $\frac{\partial b(\bar{t})}{\partial \theta}$ is rather unpenetrable. It is clear from (57) that a necessary condition for $\frac{\partial b(\bar{t})}{\partial \theta} \geqslant 0$ is a sufficiently high positive value of $\theta$. With $\theta \leqslant 0$, $\frac{\partial b(\bar{t})}{\partial \theta}<0$

The cause of the ambiguity of the effect from a change in $\theta$ on $b(\bar{t})$ is clear from (54). Given $\frac{M}{P L}$, a lower value of $\theta$ raises $\dot{b}$. $\frac{M}{P L}$ is endogenous, however; with $P$ non-predetermined, $\frac{M}{P L}$ can even jump discontinuously. From the monetary equilibrium condition (33) we see that $\frac{\dot{P}(t)}{P(t)}$ and $P(t)$ are positively related. If a reduction in $\theta$ were to lower $\frac{\dot{p}}{P}$ initially (the non-Sargent-Wallace case) real money balances would rise through a fall in $P$. The net effect on $\theta \frac{M}{P L}$ and on $\dot{b}$ 
is ambiguous in this case. For $b(\bar{t})$ to rise when $\theta$ is raised we require $\frac{d}{d \theta} \int_{0}^{\bar{t}} e^{(\bar{r}-n)(\bar{t}-s)} \frac{\theta M(s)}{P(s) L(s)} d s<0$ : raising the proportional rate of growth of the nominal money stock lowers the real discounted present value of the government's new money creation. To see what this implies, consider a different policy regime in which the same rate of growth of the money stock, $\theta$, is maintained forever. The convergent rational expectations solution then has $\frac{\dot{P}(t)}{P(t)}=\theta-n$ for all $t$ after any unanticipated permanent shock.

In this case $\frac{d}{d \theta}\left(\theta \frac{M}{P L}\right)=\frac{d}{d \theta}\left(\theta\left(\gamma_{1}-\gamma_{2} \frac{\dot{p}}{p}\right)\right)=\frac{d}{d \theta}\left(\theta\left(\gamma_{1}-\gamma_{2}(\theta-n)\right)\right)$

$$
=\gamma_{1}+\gamma_{2} n-2 \gamma_{2} \theta<0 \text { if } \theta>\frac{1}{2}\left(\frac{\gamma_{1}}{\gamma_{2}}+n\right)
$$

A necessary and sufficient condition for the existence of a convergent rational expectations solution and a positive steady state stock of real percapita money balances in this policy regime is $\theta-n-\frac{\gamma_{1}}{\gamma_{2}}<0$. Thus, provided $\frac{1}{2}\left(\frac{r_{1}}{\gamma_{2}}+n\right)<\theta<\frac{r_{1}}{r_{2}}+n$, inflation tax receipts deciline when the inflation rate increases. Clearly, no optimising government would push the inflation rate to the point where the demand for real money balances has greater than unit elasticity, but this outcome is possible under ad-hoc monetary rules.

If the government lowers the rate of growth of the nominal money stock permanently from an initial value greater than $\frac{1}{2}\left(\frac{\gamma_{1}}{\gamma_{2}}+n\right)$, the real value of its money issue will be higher at each point in time than it would have been at the corresponding moment under the higher rate of growth of nominal money. Therefore, if the money growth rate is lowered for a sufficiently long period of time $(0, \bar{t})$, from an initial position for which $\theta>\frac{1}{2}\left(\frac{\gamma_{1}}{\gamma_{2}}+n\right)$, the discounted value of its real money issues $\int_{0}^{\bar{t}} e^{(\bar{r}-n)(\bar{t}-s)} \frac{\dot{M}(s)}{P(s)}$ ds is also likely to be higher 
under the lower rate of nominal money growth.

Without pretending that the foregoing argument constitutes a formal proof, I would venture the conjecture that in the variable velocity version of the Sargent-Wallace model, we can have $\frac{\partial b(\bar{t})}{\partial \theta} \leqq 0$.

Consider now what happens to the rate of inflation for $0 \leqslant t<\bar{t}$ when the rate of monetary growth is reduced. Since for $0 \leqslant t<\bar{t}$

$$
\frac{\dot{P}(t)}{P(t)}=\frac{\gamma_{1}}{\gamma_{2}}-\frac{1}{\gamma_{2}} \frac{M(0)}{L(0)} e^{(\theta-n) t} \frac{1}{P(t)}
$$

we have

$$
\begin{aligned}
\frac{\partial \frac{\dot{P}(t)}{P(t)}}{\partial \theta} & =-t \frac{1}{\gamma_{2}} \frac{M(0)}{L(0)} e^{(\theta-n) t} \frac{1}{P(t)}+\frac{1}{\gamma_{2}} \frac{M(0)}{L(0)} e^{(\theta-n) t} \frac{1}{(P(t))^{2}} \frac{\partial p(t)}{\partial \theta} \\
= & \frac{M(0)}{\gamma_{2} L(0)} e^{(\theta-n) t} \frac{1}{P(t)}\left[-t+\frac{\frac{\partial P(t)}{\partial \theta}}{P(t)}\right]
\end{aligned}
$$

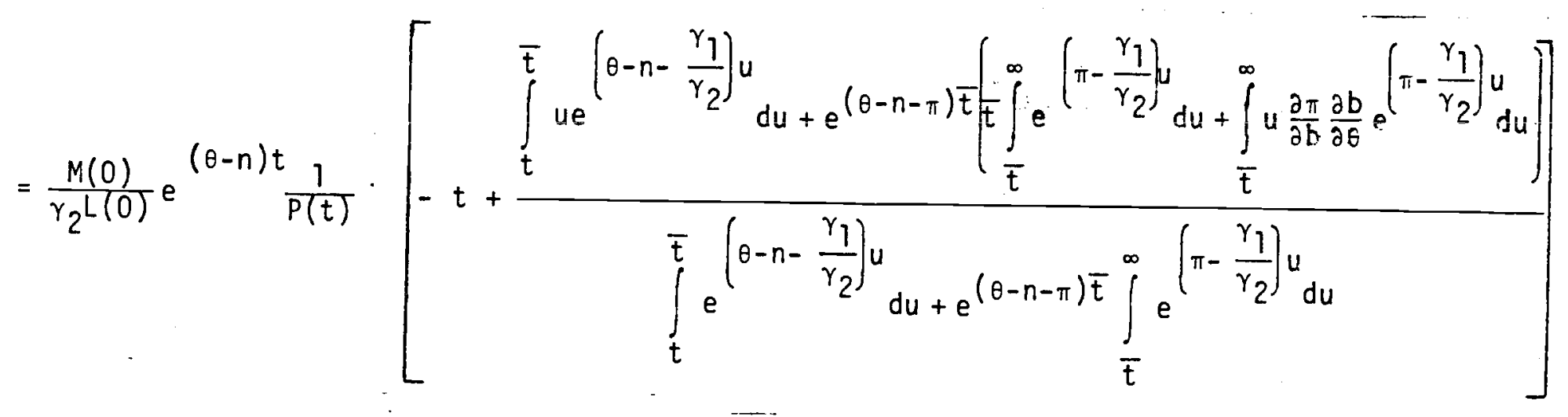

Since $\frac{\partial \pi}{\partial b(\bar{t})}$ is positive, a positive effect of $\theta$ on $b(\bar{t})$ is sufficient to give $\frac{\partial \frac{\dot{P}(t)}{P(t)}}{\partial \theta}>0$ for $0 \leqslant t<\bar{t}$. This would be the extreme non-Sargent-Wallace case: a lower rate of monetary growth lowers the rate of inflation initially (for $0 \leqslant t<\bar{t}$ ) and, by inducing a lower value of $b(\bar{t})$, lowers inflation in the future (for $t \geqslant \bar{t}$ ) as well. 
The Sargent-Wallace paradox which has a lower rate of monetary growth leading to higher inflation requires $\frac{\partial b(\bar{t})}{\partial \theta}<0$. This is necessary and sufficient to raise inflation for $t \geqslant \bar{t}$. From $(58) \frac{\partial b(\bar{t})}{\partial \theta}<0$ is necessary (but not sufficient) to give $\frac{\partial P(t)}{\partial \theta}<0$ for $0 \leqslant t<\bar{t} . \quad \frac{\partial P(0)}{\partial \theta}<0$ is necessary and sufficient for $\frac{\partial \frac{\dot{P}(0)}{P(0)}}{\partial \theta}<0$, but $\frac{\partial P(t)}{\partial \theta}<0,0<t<\bar{t}$, is necessary but not sufficient for $\frac{\partial \frac{\dot{P}(t)}{\partial(t)}}{\partial \theta}<0,0<t<\bar{t}$. The Sargent-Wallace paradox that tighter money now may imply higher inflation now and in the future has its counterpart in the possibility that tighter money now many imply lower inflation now and in the future.

A simple graphical representation of some of the rather messy algebra can be provided. Note that.

$$
\frac{d}{d t}\left(\frac{M}{P L}\right)=\left(\frac{\dot{M}}{M}-\frac{\dot{P}}{P}-n\right) \frac{M}{P L}=\left(\frac{\dot{M}}{M}-\frac{\gamma_{1}}{\gamma_{2}}-n\right) \frac{M}{P L}+\frac{1}{\gamma_{2}}\left(\frac{M}{P L}\right)^{2}
$$

In the Sargent-Wallace example $\frac{\dot{M}(t)}{M(t)}=\theta$ for $t<\bar{t}$ and $\frac{\dot{M}(t)}{M(t)}=\pi+n$ for $t \geqslant \bar{t}$, where $\pi$ is given by $\left(52^{\prime}\right)$. For simplicity and without significant loss of generality, our reference point will be a system in which $\theta, b(0)$ and $\bar{t}$ have been chosen such that the proportional rate of growth of the money supply is constant throughout, i.e. $\theta=\pi=\theta_{0}$, say. The rate of change of real per-capita money balances is therefore given by.

$$
\frac{d}{d t}\left(\frac{M}{P L}\right)=\left(\theta_{0}-\frac{\gamma_{1}}{\gamma_{2}}-n\right) \frac{M}{P L}+\frac{1}{\gamma_{2}}\left(\frac{M}{P L}\right)
$$

Equation (60) is graphed as $A A$ in the top panel of Figure $3 . \quad \frac{d}{d t}\left(\frac{M}{P L}\right)=0$ when $\frac{M}{P L}=0$ and when $\frac{M}{P L}=-\gamma_{2}\left(\theta_{0}-\frac{\gamma_{1}}{\gamma_{2}}-n\right)$. For there to exist a non-trivial stationary equilibrium with $\frac{M}{P L}>0$ we therefore require $\theta_{0}-\frac{\gamma_{1}}{\gamma_{2}}-n<0$. The non-trivial stationary equilibrium is at $E_{0}$. AA reaches a minimum at 
$\frac{M}{P L}=-\frac{r_{2}}{2}\left(\theta_{0}-\frac{r_{1}}{r_{2}}-n\right)$, hal fway 0 and $E_{0}$. The bottom panel of Figure 3 graphs the relationship $\frac{\dot{p}}{p}=\frac{r_{1}}{r_{2}}-\frac{1}{r_{2}} \frac{M}{P L}$.

An unanticipated permanent reduction in the rate of monetary growth to $\theta_{1}<\theta_{0}$ raises the long-run real per-capita stock of money balances to $E_{1}$ say, and shifts the AA locus to $A^{\prime} A^{\prime}$. The price level falls immediately as the economy moves instantaneously from $E_{0}$ to $E_{1}$ and stays there. The rate of inflation falls immediately from $\theta_{0}-n$ to $\theta_{1}-n$. A previously unanticipated future permanent increase in the rate of monetary growth to $\theta_{2}>\theta_{0}$ at $t=\bar{t}$, results in an immediate increase in the price level (at $t=0$ ) which places the system in Figure 4 somewhere on $A A$ between $E_{0}$ and $E_{02}$, say at $E_{01}$. From there it moves gradually along $A A$ towards $E_{02}$, where it arrives at $t=\bar{t}$ when the rate of monetary growth is actually increased. At $t=\bar{t}$ the system jumps from $E_{02}$ to $E_{2}$. Neither $P$ nor $\frac{\dot{p}}{P}$ jump at $t=\bar{t}$. At $t=0$ the rate of inflation jumps up to $\left(\frac{P}{P}\right)_{01}$. After that it continues to increase gradually to $\theta_{2}-n$. $E_{01}$ will be closer to $E_{02}$ the closer the implementation date $(\bar{t})$ is to the announcement date (0)

The Sargent-Wallace paradox can be represented as a previously unanticipated immediate temporary reduction in $\frac{\dot{M}(t)}{M(t)}$ (for $0 \leqslant t<\bar{t}$ ) followed by future permanent increase in $\frac{\dot{M}(t)}{M(t)}$ at $t=\bar{t}$ beyond its original value. This is depicted in Figure 5: Up to $t=0$, the system is at $E_{0}$ with the rate of inflation given by $\left(\frac{P}{P}\right)_{0}$. At $t=0$ the system jumps onto $A^{\prime} A^{\prime}$ to a position such as $E_{01}$ or $E_{01}{ }^{\prime}$. From $t=0$ to $t=\bar{t}$ the system moves smoothly along $A^{\prime} A^{\prime}$ to $E_{02}$ where it arrives when $t=\bar{t}$. At $t=\bar{t}$ the system moves to $E_{2}$.

It is clear that it is possible for the rate of inflation at $t=0$ to rise in spite of the temporary reduction in monetary growth. If the system were to move to $E_{01}{ }^{\prime}$, the rate of inflation at $t=0$ jumps to $\left(\frac{\dot{p}}{p}\right)_{01}^{\prime}>\left(\frac{\dot{p}}{p}\right)_{0}$ : the rate of inflation is higher throughout the adjustment process than it was at $E_{0}$. 
FIGURE 3

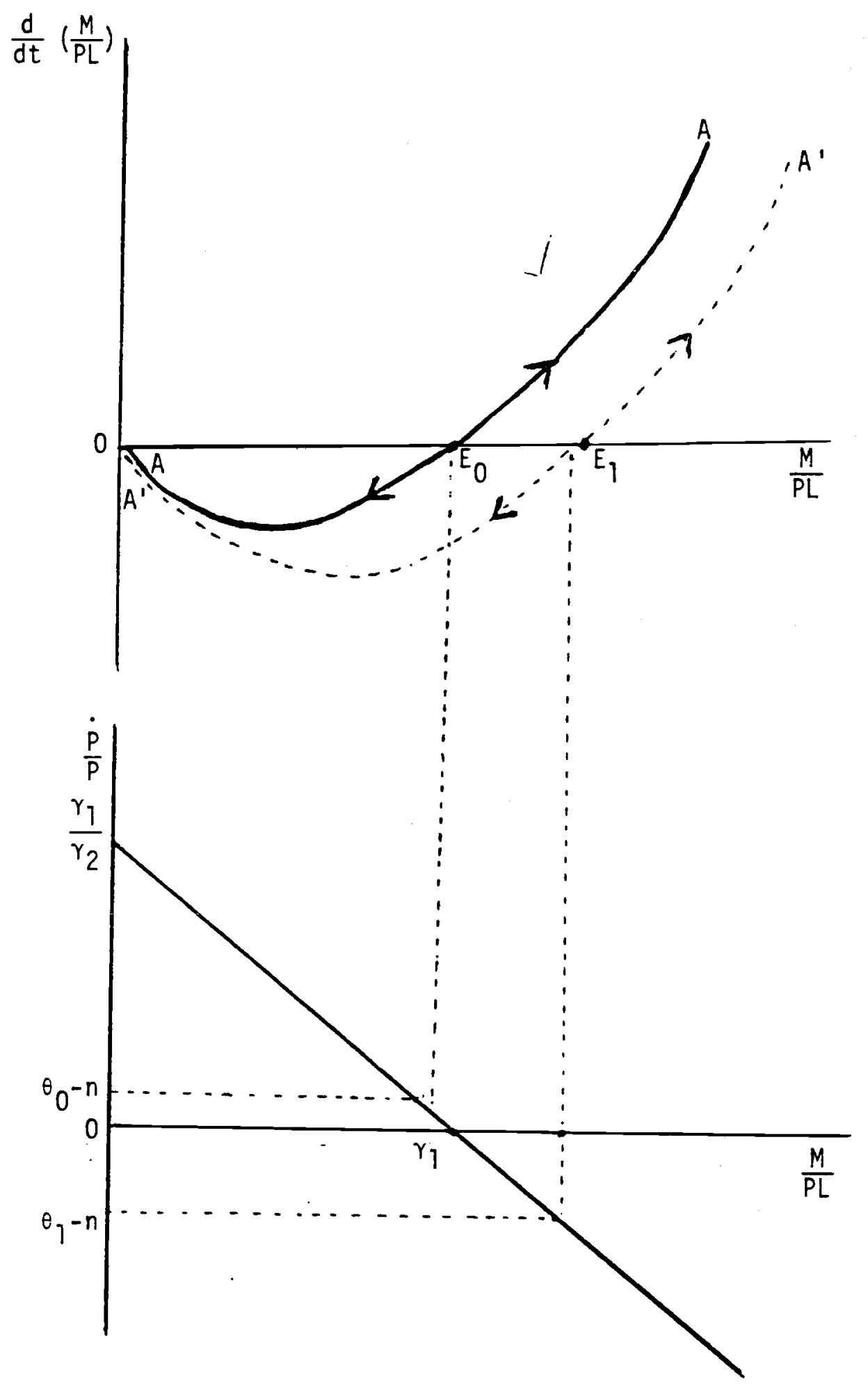


FIGURE 4

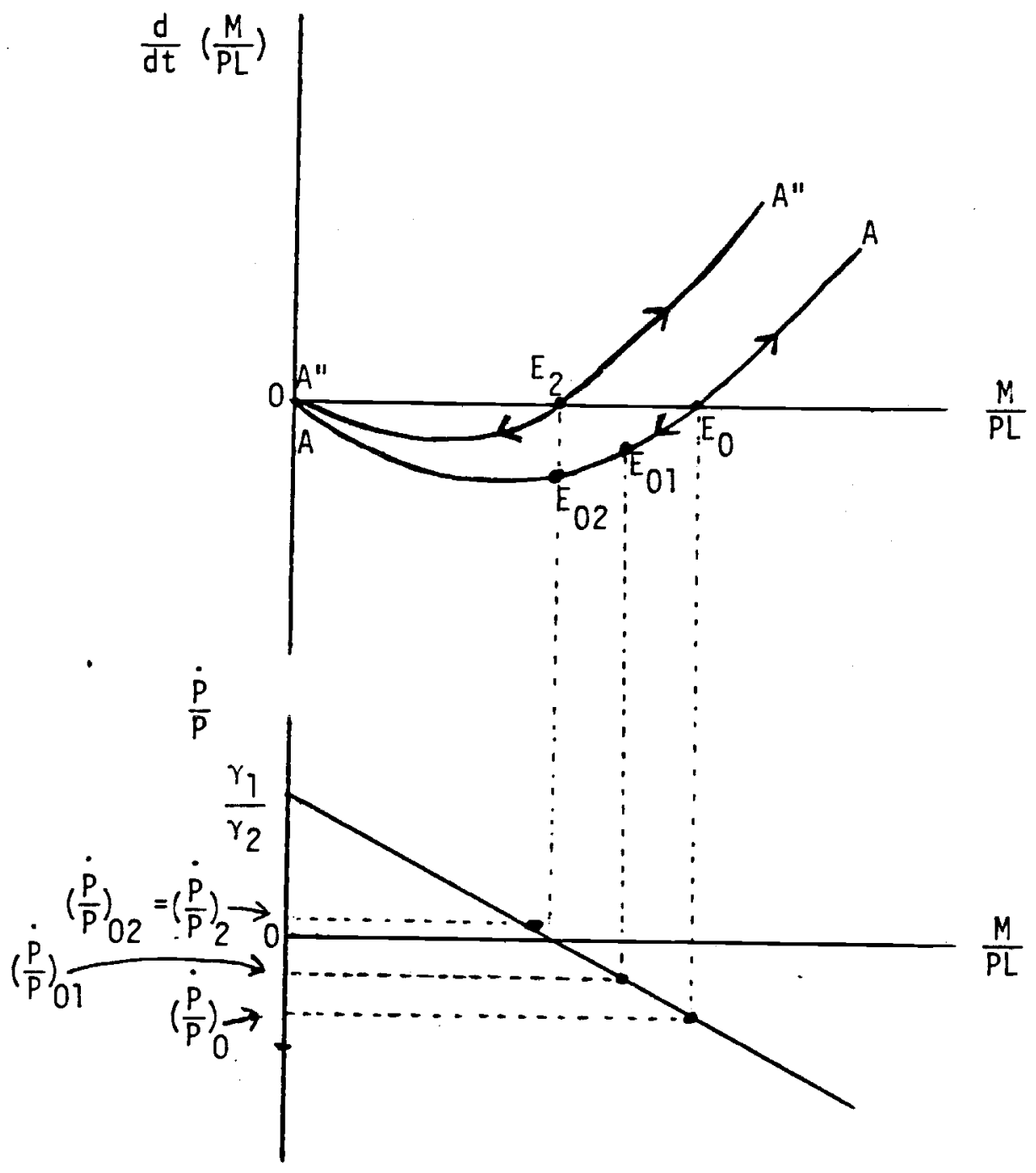


FIGURE 5

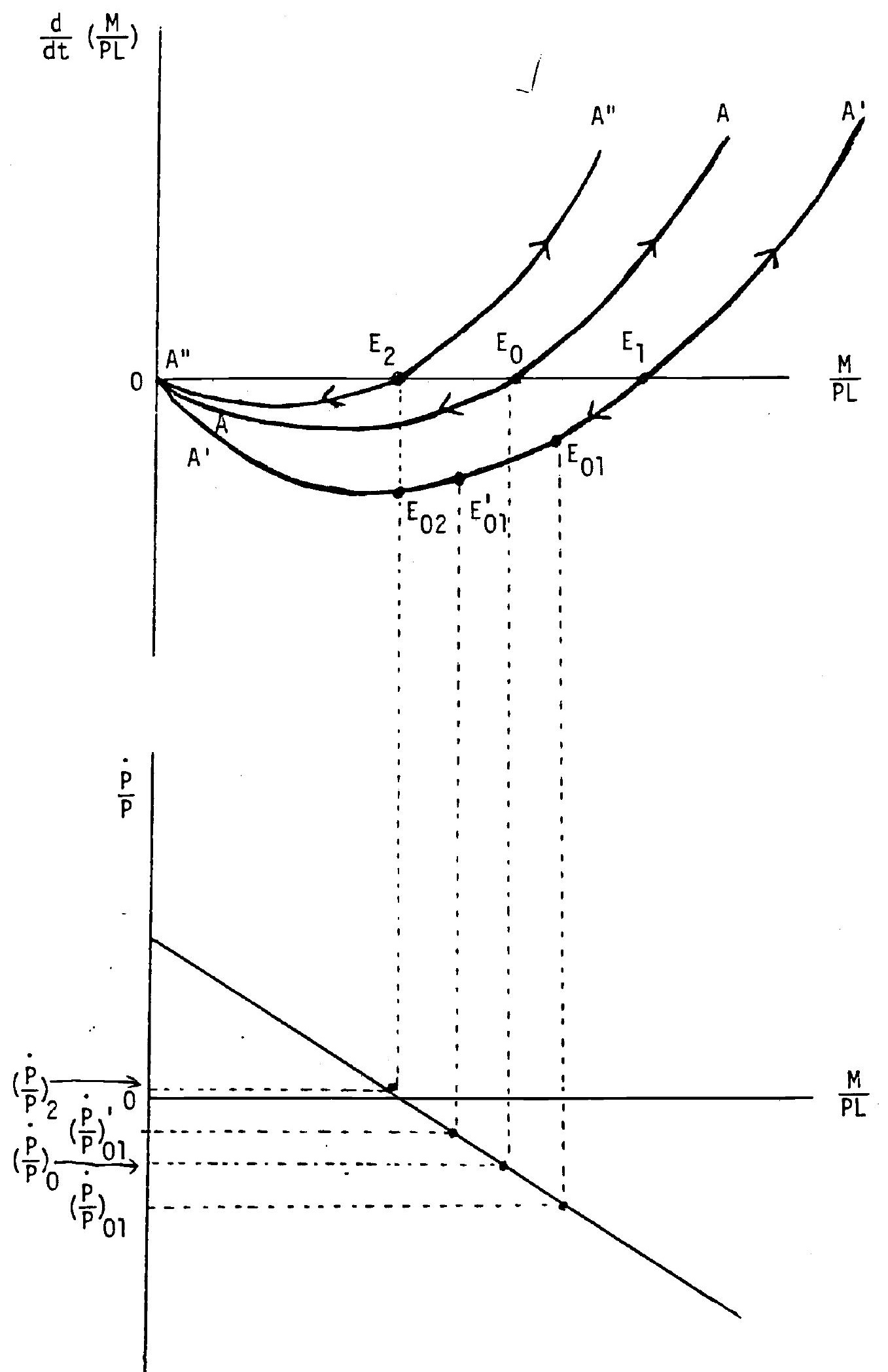


Since at $E_{01}$ ' the price level is also above its value at $E_{0}$, the price level path is also higher throughout. It is also clear that even if the temporary reduction in money growth is followed by a rate of monetary growth that is higher than the initial rate, the impact effect on the price level and the rate of inflation may well be negative. A move to $E_{01}$ at $t=0$ would generate this outcome.

In the extreme non-Sargent-Wallace case, an initial reduction in money growth $\left(\theta_{1}<\theta_{0}\right)$ is followed, after $t=\bar{t}$ by a rate of monetary growth that also lies below $\theta_{0}$, though not necessarily below $\theta_{1}$. The case where $\theta_{0}>\theta_{2}>\theta_{1}$ is depicted in Figure 6 . Here the systems jump at $t=0$ to $E_{01}$ on the (divergent) solution path corresponding to $\theta_{1}$. It then moves smoothly between $t=0$ and $t=\bar{t}$ along $O A^{\prime}$ towards $E_{02}$. At $t=\bar{t}$ it jumps from $E_{02}$ to $E_{2}$. Both the price level and the rate of inflation decline at $t=0$ and both stay throughout below what they would have been in the absence of the policy change.

In the remaining sections of the paper we return to the constant velocity case with $\gamma_{2}=0$.

\section{(3c) An endogenous real interest rate}

The analysis is not affected significantly if we endogenise the real interest rate by postulating an inverse relationship between the real interest rate and the capital-labour ratio, i.e. (35) becomes

$$
r(t)=r\left(\frac{K(t)}{L(t)}\right) \quad r^{\prime}<0
$$

From (37) we know that once $\frac{B}{P L}$ is held constant, $\frac{K}{L}$ will also be constant. Indeed since $k(t)=e^{n t}\left[K(0)+\frac{B(0)}{P(0)}\right]-\frac{B(t)}{P(t)}$ we can rewrite $\left(35^{\prime}\right)$ as

$$
r(t)=r\left(\bar{W}-\frac{B}{L P}\right) \text { where } \bar{W} \equiv\left[K(t)+\frac{B(t)}{P(t)}\right] L(t)^{-1}=\left[K(0)+\frac{B(0)}{P(0)}\right] L(0)^{-1}
$$




\section{FIGURE 6}

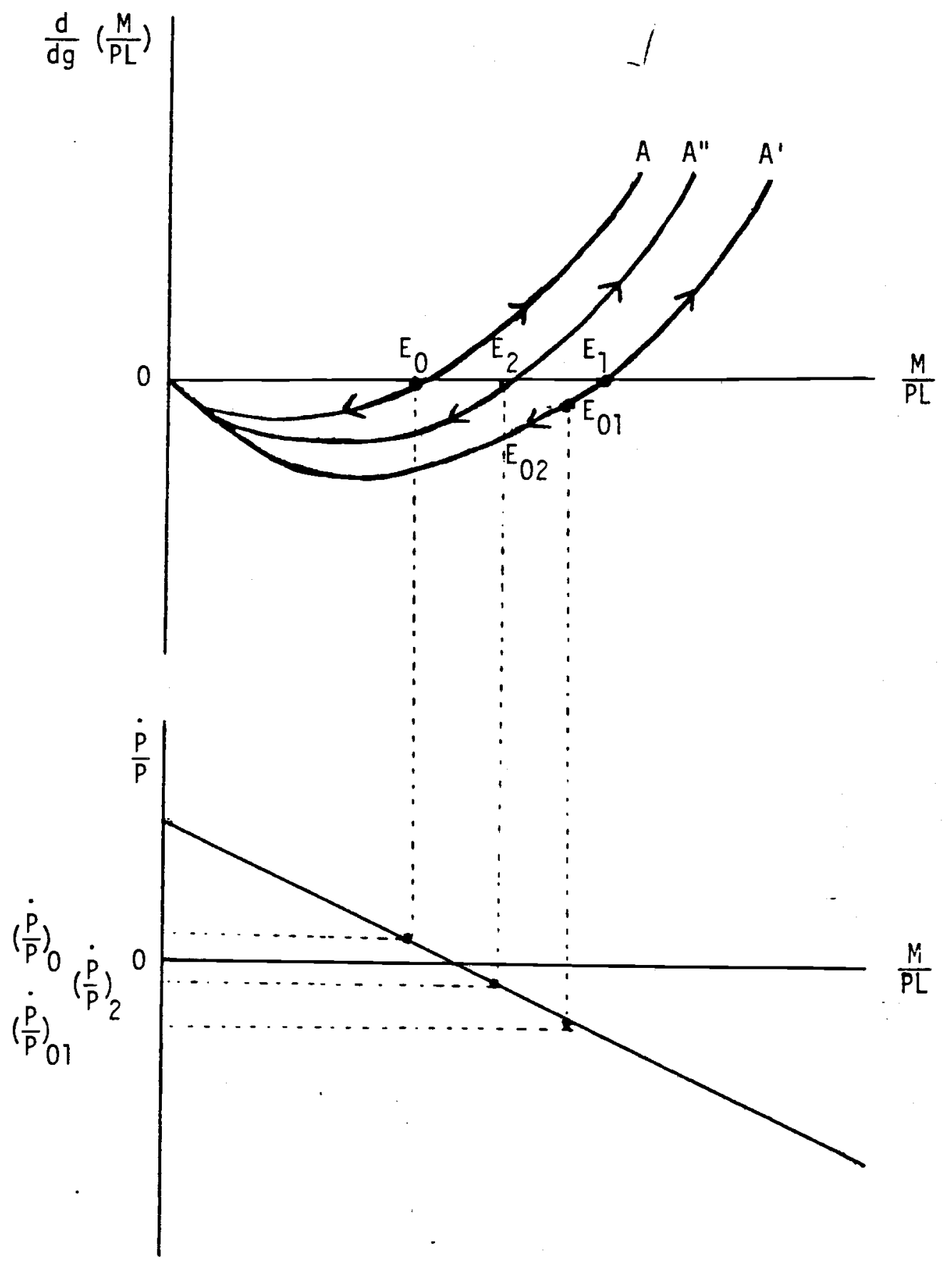


With $\gamma_{2}=0$, the rate of inflation for $t \geqslant \bar{t}$ is given by

$$
\frac{\dot{P}(t)}{P(t)}=\frac{1}{r_{1}}\left[\delta(t)+\left(r\left(\bar{w}-\frac{B(\bar{t})}{P(\bar{t}) L(\bar{t})}\right)-n\right) \frac{B(\bar{t})}{P(\bar{t}) L(\bar{t})}\right]-n \quad t \geqslant \bar{t}
$$

The effect of a larger stock of real public debt per-capita on the rate of inflation for $t \geqslant \bar{t}$ is given by

$$
\frac{\partial\left(\frac{\dot{P}(t)}{P(t)}\right]}{\partial\left(\frac{B(\bar{t})}{P(\bar{t}) L(\bar{t})}\right)}=\frac{1}{r_{1}}\left[(r-n)-\frac{B(\bar{t})}{P(\bar{t}) L(\bar{t})} r^{\prime}\right]>\frac{1}{r_{1}}(r-n)>0 \text { if } r>n \text {. }
$$

Thus a higher value of $b(\bar{t})$ raises inflation for $t \geqslant \bar{t}$ by more when $r$ is endogenous than when $r$ is exogenous. To determine what happens to $b(\bar{t})$ when $\theta$ is lowered we specialise (35") to the linear function

$\left(35^{\prime \prime \prime}\right) \quad r=n+\phi b$

$$
\begin{aligned}
\phi & >0 \\
0 \leq b & \leq \bar{W}
\end{aligned}
$$

For $t<\bar{t}$, the rate of change of $b$ is governed by

$$
\dot{b}(t)=\delta(t)-\theta \gamma_{1}+(r-n) b
$$

or

$$
\dot{b}(t)=\delta(t)-\theta \gamma_{1}+\phi b(t)^{2}
$$

We shall consider the case where $\delta(t)=\delta$. The graph of equation (61) is shown in Figure 7. If the non-monetised part of the deficit, $\delta-\theta \gamma_{j}$, is negative, there are two stationary equilibria, $\pm \sqrt{\frac{\theta \gamma_{1}-\delta}{\phi}}$, shown as $b_{1}$ and $b_{2}$ in Figure 7a. We believe it to be more in the spirit of the Sargent and Wallace exercise to consider the case where $\delta-\theta \gamma_{1}$ is positive shown in Figure 7a. In this case the solution of (61) is given by 


\section{FIGURE 7}

Note: the figures are parabolas with a minimum at $\delta-\gamma_{1} \theta$ and symmetric about the vertical axis.
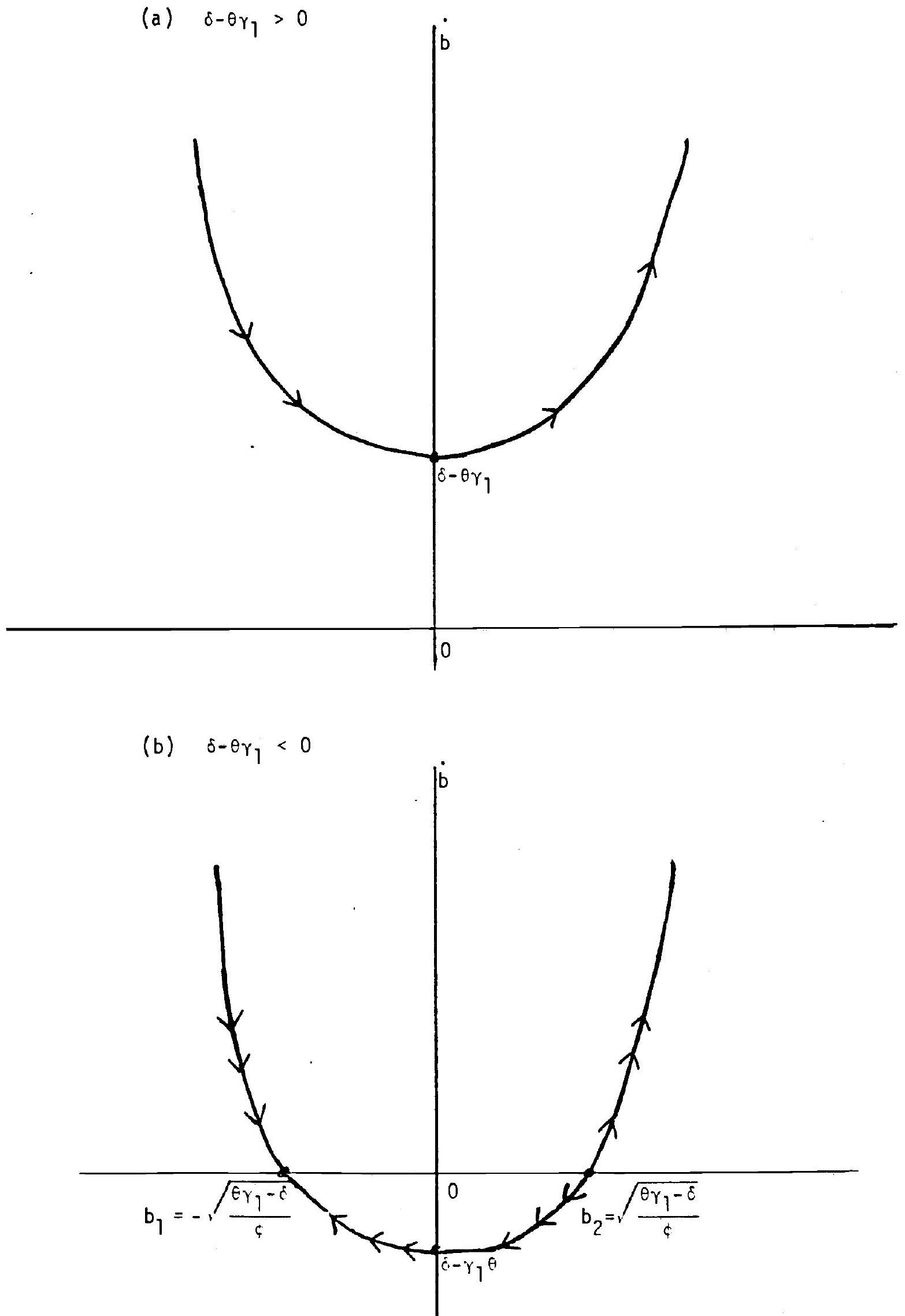
(62)

$$
b(t)=\tan \left(t \sqrt{\left(\delta-\theta \gamma_{1}\right)_{\phi}}+c\right) \sqrt{\frac{\delta-\theta \gamma_{1}}{\phi}}
$$

If $b(0)=\bar{b}(0)$, the arbitrary constant $C$ is given by

$$
C=\arctan \left[\bar{b}(0)\left(\frac{\delta-\theta \gamma_{1}}{\phi}\right)^{-\frac{1}{2}}\right]
$$

Therefore

$$
\frac{\partial b(\bar{t})}{\partial \theta}=-\frac{1}{2}\left[\frac{\bar{t}}{\cos ^{2}(z)}-\frac{\left(\delta-\gamma_{1} \theta\right)^{-1} \bar{b}(0)}{\cos ^{2}(z)\left[1+\frac{2}{b}(0)\left(\frac{\delta-\theta \gamma_{1}}{\phi}\right)^{-1}\right]}+\frac{\tan (z)}{\sqrt{\left(\delta-\theta \gamma_{1}\right) \phi}}\right] \gamma_{1}
$$

where

$$
z=\bar{t} \sqrt{\left(\delta-\sigma \gamma_{1}\right) \zeta}+\arctan \left[\bar{b}(0)\left(\frac{\delta-\varepsilon \gamma_{1}}{\varphi}\right)^{-\frac{1}{2}}\right]
$$

We only consider solutions in the range $0 \leqslant b(t) \leqslant \bar{W}$. Since tan is a periodic function with $\tan (\pi \cdot k)=0, k=0,1,2, \ldots, \quad \tan ^{\prime}(x)>0$ and $\lim \tan \left(x^{-}\right)=+\infty$,

$$
x \rightarrow \frac{\pi}{2}+k \pi
$$

we note that when the interest rate rises 1 inearly with $b$, the growth of $b$ is so strong that it tends to infinity in finite time. With $\tan (z) \geqslant 0$ by assumption, $\frac{\partial b(\bar{t})}{\partial \theta}$ will be negative provided the initial stock of bonds, $b(0)$ is not too large. In this sense, the conclusion of Sargent and Wallace that a lower rate of growth of money for $0 \leqslant t<\bar{t}$ raises $b(\bar{t})$ (and raises inflation for $t \geqslant \bar{t}$ ) remains valid in the constant velocity model when the real interest rate is endogenised in the manner suggested above.

\section{(3d) Public Sector Capital Formation}

If public sector expenditure on goods and services is not merely of the hole-in-the-ground public consumption variety, the monetary implications of the deficit can only be accurately assessed by making a correction for net public sector capital formation. Let $C^{G}$ denote public sector consumption, ${ }_{C_{2}}{ }^{I}$ public sector capital formation, $k^{G}$ the public sector capital stock, 
$K^{P}$ the private sector capital stock and $r^{G}$ the real rate of return on public sector capital. We only consider the case where both $r_{G}$ and the rate of return on private capital, $r$, are exogenous. Government bonds still yield the same expected real rate of return as can be earned from the ownership of capital. We assume that the government appropriate the return on its capital stock, $r^{G} K^{G}$.

The budget constraint is now (66) $\quad \frac{\dot{M}+\dot{B}}{P}=G^{C}+G^{I}+i \frac{B}{P}-T-r^{G} K^{G}$

Extending the Sargent-Wallace policy rules we now assume that for $t \geqslant \bar{t}$ both $\frac{B}{L P}$ and $\frac{K^{G}}{L}$ are kept constant, i.e. $\frac{\dot{B}}{L P}=\left(n+\frac{\dot{P}}{P}\right) \frac{B}{L P}$ and $\frac{\dot{K}^{G}}{L} \equiv \frac{G^{I}}{L}=n K^{G}$. The rate of inflation in $t \geqslant \bar{t}$ is now given by

$$
\frac{\dot{P}(t)}{P(t)}=V(t)\left[\frac{G(t)-T(t)}{Y(t)}+(r-n)\left(\frac{B(\bar{t})}{P(\bar{t}) Y(\bar{t})}-\frac{K(\bar{t})}{Y(\bar{t})}\right)+\left(r-r^{G}\right) \frac{K(\bar{t})}{Y(\bar{t})}\right]-n \text { * }
$$

If the rate of return from government capital formation $r^{G}$, equals the marginal cost of borrowing $r$, the measure of the deficit relevant for inflation is the "inflation-and-growth-corrected", government current account or consumption account deficit. Net capital formation by the public sector in the long-run creates income equal, in present value, to the cost of borrowing incurred to finance sucti expenditure. There are no long-run inflationary implications of such expenditures. Obvious adjustments have to be made if the rate of return on public capital exceeds or falls short of the cost of borrowing The use even of the inflation-and-growth corrected deficit $\frac{G^{C}+G^{I}-T}{Y}+(r-n) \frac{B}{\text { PY }}-r^{G} \frac{k^{G}}{Y}$ to infer the long-run inflationary implications of the fiscal stance amounts to assuming, implicitly, that $r^{G}=0$ for new public sector investment i.e. that additional public sector capital formation is entirely unproductive.

Even if we maintain the strong Sargent-Wallace assumption of one-for-one 
crowding out of private capital formation by public borrowing, total national (private plus public) capital formation will of course be invariant under bondfinanced increases in public sector capital formation.

\section{(3e) Cyclical corrections}

A common feature of the tax-transfer structure in most industrialised countries is the dependence of net tax receipts on the current level of economic activity, $Y$. A simple linear tax function without an intercept will suffice for our purposes.

$$
T=t_{1} Y, \quad 0<t_{1}<1
$$

We continue to treat public expenditure on goods and services as exogenous: it is assumed to grow at the natural rate of growth, $n$. Trend output is denoted by $P(t)=L(t)$.

If output is subject to cyclical fluctuations around a trend, then $\frac{G(t)-T(t)}{Y(t)}$ is likely to give a misleading impression of the long-run inflationary implications and the crowding out consequences of the fiscal stance whenever output deviates from its trend level. Note that it is not necessary to identify such cycles in the level of economic activity with "Keynesian" deviations of actual from full employment output. For present purposes they might as well represent serially correlated movements in the "natural" or full employment level of output. Quite separate issues arise when past, current and prospective future fiscal and monetary policy actions themselves contribute to endogenous cyclical movements in the level of economic activity. E.g. the issues raised by $B$ inder and Solow (1973), concerning the appropriate "multiplier" weights to be attached to the various fiscal instruments, are not germane to the point made here.

Consider again a policy regime which fixes the rate of growth of the nominal stock of money, $\theta$, up to $t=\bar{t}$, financing any resulting deficit (given the parameters of the expenditure and tax functions, $g=\frac{G}{\bar{P}}$ and $t_{1}=\frac{T}{\mathrm{P}}$, by borrowing. After $t=\bar{t}$ the real per capita stock of government interest-bearing debt is held constant. Equations (69) and (70) are not model-specific: 
(69)

$$
\frac{d}{d t}\left(\frac{B(t)}{P(t) Y(t)}\right)=g-t_{1} \frac{Y(t)}{P(t)}+\left((r-n) \frac{B(t)}{P(t) Y(t)}-\theta \frac{M(t)}{P(t) Y(t)}\right) \frac{Y(t)}{P(t)}
$$

$$
0 \leqslant t<\bar{t}
$$

(70)

$$
\frac{\dot{M}(t)}{M(t)}=V\left[g \frac{\bar{Y}(t)}{Y(t)}-t_{1}+(r-n) \frac{B(\bar{t})}{P(\bar{t}) Y(\bar{t})} \frac{\bar{Y}(t)}{Y(t)}\right]
$$

Trend crowding out pressure is measured by equation (69) which describes the evolution of the real per-capita (or per unit of trend output) stock of government bonds for a given monetary growth rate. The inflationary implications of the fiscal stance in the long-run are captured by $(70)$ which describes the "eventual monetisation of the deficit" after the system has reached some upper bound for $\frac{B}{P L}$ :

For simplicity I shall only consider the case where the velocity of circulation $V \equiv \frac{P Y}{M}$ is constant. The last two equations then become

$$
\frac{d}{d t}\left[\frac{B(t)}{\bar{Y}(t) P(t)}\right]=g+(r-n) \frac{B(t)}{P(t) \bar{Y}(t)}-\left(t_{1}+\frac{\theta}{V}\right) \frac{Y(t)}{P(t)} \quad 0 \leqslant t \leqslant \bar{t}
$$

$$
\frac{\dot{M}(t)}{M(t)}=V\left[g+(r-n) \frac{B(\bar{t})}{P(\bar{t}) \bar{Y}(\bar{t})}\right] \frac{Y(t)}{Y(t)}-V t_{1}
$$

If there are cyclical deviations of output from trend, i.e. if $\frac{Y}{Y}$ is cyclical (e.g. $\left.\frac{Y(t)}{Y(t)}=A \cos (w t+\varepsilon)+1\right)$, long-run crowding out pressure will be overstated (understated) by the momentary rate of change of $\frac{B}{\mathrm{YP}}$ whenever output falls below (rises above) its trend. Once $\frac{B}{Y P}$ has reached its upper bound, the trend rate of growth of the money stock (and thus the average rate of inflation) will be overstated (understated) by the current rate of growth of the money supply whenever output falls below (rises above) its trend value. To get a proper picture of long-run crowding out pressure $\left(69^{\prime}\right)$ should be evaluated at $Y=Y$. The 
implications of the fiscal stance for inflation in the long-run are similarly obtained by evaluating (70') at $Y=\bar{Y}$. "Cyclical corrections" are therefore merely a convenient procedure for estimating the trend or permanent deficit. If departures from trend output are not of a regular cyclical nature and if upward and downward deviations from trend do not tend to balance each other out, the convenient short-hand measure of the permanent deficit obtained by evaluating the deficit at $Y(t)=\bar{Y}(t)$ will be inappropriate. Explicit estimates of the future expected paths of the deficit will have to be made instead.

If we take a Keynesian view of business cycles, and model output as demand-determined, the endogeneity of $\frac{Y}{Y}$ creates the danger that mistaken inferences concerning the fiscal stance will lead to destabilising "corrective" fiscal actions. (This requires us to drop the assumption of a constant velocity, which would deprive fiscal policy (changes in $g$ and $t_{\eta}$ ) of any short-run impact on effective demand). Clearly if $\frac{Y}{\bar{Y}}=\varepsilon\left(g, t_{1}, \ldots\right)$ with $\varepsilon_{g},-\varepsilon_{t_{1}}>0$, a large conventionally measured deficit which corresponded to a small-inflation-and-growth-corrected, cyclically adjusted government current account deficit as a proportion of GDP, might provide the signal for cuts in public spending or increases in tax rates that lower the level of effective demand and output. Such measures would be quite unwarranted in the sense that maintaining the fiscal stance (or even reducing $t$, and/or raising g) would be consistent with a secular decline in $\frac{B}{P \bar{Y}}$ (holding $\theta=\frac{M}{M}$ at the long-run non-inflationary value of $n$ ) or a zero trend rate of inflation (holding $\frac{B}{P \bar{Y}}$ constant). 


\section{CONCLUSIONS}

There should be a moratorium on simplistic statements about causal links between conventionally measured public sector financial deficits, crowding out of capital formation and inflation. 


\section{REFERENCES}

Blinder, A.S. and Solow, R.M. (1973), "Does Fiscal Policy Matter?", Journal of Public Economics, 2, 319-38.

Buiter, W.H. (1977a), "Crowding Out and the Effectiveness of Fiscal Policy", Journal of Public Economics, 7, June, pp. 309-328.

....... (1977b), "An Integration of Short-Run Neo-Keynesian Models and Long-Run Growth Theory", De Economist, pp. 340-59.

(1979), Temporary Equilibrium and Long-run Equilibrium, Gariand Publishing Inc. (Yale University Ph.D. Thesis 1975).

(1981), "Comment on T.J. Sargent and N. Wallace: 'Some Unpleasant Monetarist Arithmetic'", London School of Economics, Centre for Labour Economics, Discussion Paper No. 113, December.

......... (1982a), "Saddlepoint problems in continuous time rational expectations models: a general method and some macroeconomic examples", forthcoming, Econometrica.

(1982b), "The Proper Measurement of Government Budget Deficits:

Comprehensive Wealth Accounting or Permanent Income Accounting for the

Public Sector: Its Implications for Policy Evaluation and Design"

London School of Economics, Centre for Labour Economics, Discussion Paper No. 140 , October.

Cagan, P. (1956), "The Monetary Dynamics of Hyperinflation" in M. Friedman ed. Essays in the Quantity Theory of Money, University of Chicago Press. Sargent, T.J. and Wallace, N. (1981), "Some Unpleasant Monetarist Arithmetic". Unpublished, November.

Sidrauski, M. (1967), "Rational Choice and Patterns of Growth in a Monetary Economy", American Economic Review, 57, May, pp. 534-544. 
Threadgold, A.R. and Taylor, C.T. (1979), "Real' National saving and its sector composition", Discussion Paper No. 6, Bank of England, October.

Tobin, J. and Buiter, W.H. (1976), "Long Run Effects of Fiscal and Monetary

Policy on Aggregate Demand", in J. Stein ed., Monetarism, Amsterdam,

- North Holland.

Formation and Economic Activity", in G. von Furstenberg ed. The Government and Capital Formation, Ballinger. 